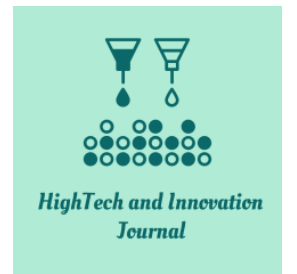

ISSN: $2723-9535$

\title{
Production Data Analysis Techniques for the Evaluation of the Estimated Ultimate Recovery (EUR) in Oil and Gas Reservoirs
}

\author{
Saber Kh. Elmabrouk ${ }^{1}$, Walid Mohamed Mahmud ${ }^{2 *} \odot$ \\ ${ }^{I}$ Chemical \& Petroleum Engineering, School of Engineering and Applied Science, The Libyan Academy, Tripoli, Libya. \\ ${ }^{2}$ Department of Petroleum Engineering, Faculty of Engineering, University of Tripoli, Tripoli, Libya.
}

Received 23 November 2021; Revised 18 January 2022; Accepted 26 January 2022; Published 01 March 2022

\begin{abstract}
The calculation of oil reserves (estimate ultimate recovery, EUR) is required for reservoir management. It is important to differentiate between oil reserves and oil resources. The latter is roughly defined as the sum of recoverable and unrecoverable volumes of oil in place; whereas, the oil reserves can be defined as those amounts of oil anticipated to be commercially recoverable from a given date under defined conditions. However, there is always uncertainty when making reserve estimates, and the main source of uncertainty is the lack of available geological data. Depending on the quantity and quality of the available data, different methods are used for the evaluation of the EUR. A number of essentially straight-line extrapolation techniques (production data analysis) have been proposed to estimate the EUR for oil and gas wells. Thus, a detailed analysis of past performance of oil and water production data is required in order to predict the future performance of the oil and gas wells. This work utilized seven straight-line extrapolation techniques to estimate and compare the values of EUR of three oil wells from the same reservoir. The comparison shows very similar estimated EUR.
\end{abstract}

Keywords: Estimated Ultimate Recovery; Water Oil Ratio; Reserve; X-plot; Production Data Analysis; Decline Curve Analysis.

\section{Introduction}

The calculation of expected initial oil in place and estimated ultimate recovery (EUR) of oil and gas wells are required for evaluation and reservoir management purposes. It is important to differentiate between oil reserves (EUR) and initial oil in place. The latter is roughly defined as the sum of recoverable and unrecoverable volumes of oil in place. Whereas, the oil reserves can be defined as those amounts of oil anticipated to be commercially recoverable by applying development projects to known accumulations from a given date under defined conditions. However, there is always uncertainty when making reserve estimates. The main source of uncertainty is the lack of available geological data. Depending on the quantity and quality of the available data, different methods are used for the evaluation of the EUR [1-3]. For example, in the initial stage of development of the hydrocarbon deposit, there is very little information available; therefore, approximate estimates are usually made using analog or volumetric calculations. Considering that, in the late stage of reservoir development, production data analysis and reservoir simulation methods are commonly employed. However, it is worthwhile to mention that the EUR is the most important step toward taking any decisions regarding drilling activities, field development and reservoir management. Simultaneously, it is the most difficult aspect of reservoir engineering, especially in the early life of the reservoir. Several methods are used to

* Corresponding author: w.mahmud@uot.edu.ly

\section{doi) http://dx.doi.org/10.28991/HIJ-2022-03-01-09}

$>$ This is an open access article under the CC-BY license (https://creativecommons.org/licenses/by/4.0/).

(C) Authors retain all copyrights. 
estimate an EUR, and the methods differ depending upon the purpose of the study and availability of the data. Mainly, there are six methods available in the literature to estimate the oil and gas reserves; Volumetric Method [4], Material Balance Method [5], Production Decline Analysis (DCA) [6], Type Curve Analysis (TCA) [7], Numerical Simulation Method [8], Water Oil Ratio (WOR) [9] data analysis.

Commonly, oil and water production data are regularly measured with time. Most oil wells which are produced by natural water drive or a pressure maintenance waterflood will produce water along with oil during their life. Oil and water production history can be used in a number of ways; however, the DCA, and WOR data analysis techniques are utilized in this study where the historical oil and water production data for three selected oil wells was analyzed in order to determine EUR. In most cases, WOR is used as an analytical tool. WOR data is a performance-based method of trending future water production for the purpose of forecasting oil production, water production, and determining expected EUR. Water-cut (WC) or water fractional flow $\left(f_{w}\right)$ and oil-cut or oil fractional flow $\left(f_{o}\right)$ are alternatives ratio forecasting methods to WOR. All the proposed techniques consider straight-line relationship techniques and extrapolating the past performance on the plot.

A number of essentially empirical methods have been proposed in the literature to evaluate the waterflood performance and to calculate the EUR that consider the linearity of late-time behavior of the WOR. The objective of those efforts was to provide a semi-analytical representation for natural water drive and/or waterflooding mechanisms in oil production. Nevertheless, the oil production decline is caused by reduction in oil saturation and oil relative permeability. Unfortunately, in most cases, this method is applicable only for the analysis of late stage of a waterflood (for values of WC greater than 50\%). The expression for the steady-state radial flow of oil and water are presented in Equation 1. Simultaneously, $f_{w}$ in the reservoir is the ratio of the water production rate and the total liquid production as illustrated in Equations 2 and 3. Likewise, oil fractional flow, $f_{o}$, is the ratio of the oil production to the total liquid production.

$q=\frac{k h}{141.2 B \mu} \frac{1}{\ln \left(\frac{r_{e}}{r_{w}}\right)} \Delta p$

$f_{w}=\frac{q_{w}}{q_{w}+q_{o}}$

From 1 and 2 we get:

$f_{w}=\frac{1}{1+\frac{k_{O} \mu_{W} B_{W}}{k_{W} \mu_{o} B_{O}}}$

$f_{o}=\frac{q_{o}}{q_{w}+q_{o}}$

Since all the used techniques to establish the EUR mentioned are depending on a straight-line trend, Espinel and Barrufet (2009) [10] wondered about the accuracy of the selection of the straight-line zone. Is the straight-line zone always present? How long is it? Is it always correct to extrapolate it to find ultimate recovery at an assumed economic limit? Where does the straight-line zone begin and where does it end? They developed an alternative technique, based on multiple regression analysis, to calculate reservoir performance and EUR. The proposed method provides slops and intercepts of straight line zone of the plot of the WOR versus recovery factors from the water breakthrough time to the point where the maximum economic recovery factor.

Generally speaking, the lifecycle of an oilfield is typically characterized by three main stages: production build-up, plateau production, and declining production. Sustaining the levels of production required during the duration of the life cycle requires a good understanding and the ability to control the recovery mechanisms involved. One of the more significant key elements that effecting oil production rates during the life cycle of the field is downhole environment. It was confirmed by Ben Mahmud et al. (2016) [11] and Busahmin et al. (2017) [12] that when production wells were drilled and completion properly, they show a significant impact on the oil recovery.

\section{Oilfield Case Studies}

A detailed analysis of the past oil, gas and water production performance was conducted for the simultaneous evaluation of EUR. However, due to the uncertainty in the accuracy of extrapolation methods, as well as the lack of a completely rigorous mathematical basis, this study applies seven different extrapolation techniques:

- Decline curve analysis

$\circ \log \left(q_{o}\right)$ versus production time, $t$;

$\circ q_{o}$ versus $N_{p}$;

○ $1 / q_{o}$ versus $t_{o}$; 
- WOR extrapolated methods

○ $\log \left(f_{w}\right)$ versus $N_{p}$;

$\circ f_{o}$ versus $N_{p}$;

○ $1 / f_{w}$ versus $N_{p}$, and;

- X-plot technique

○ $N_{p}$ versus $X$-function.

Such an approach would provide a validation for the EUR results, and although there is no single perfect extrapolation technique, comparing the results obtained from different methods would provide consistency and a validation element. In this case study, three oil wells (A-01, A-06 and A-28) from a Libyan oilfield located in Sirte Basin (Figure 1) were selected to utilize seven straight-line extrapolation techniques to estimate and compare the values of EUR.

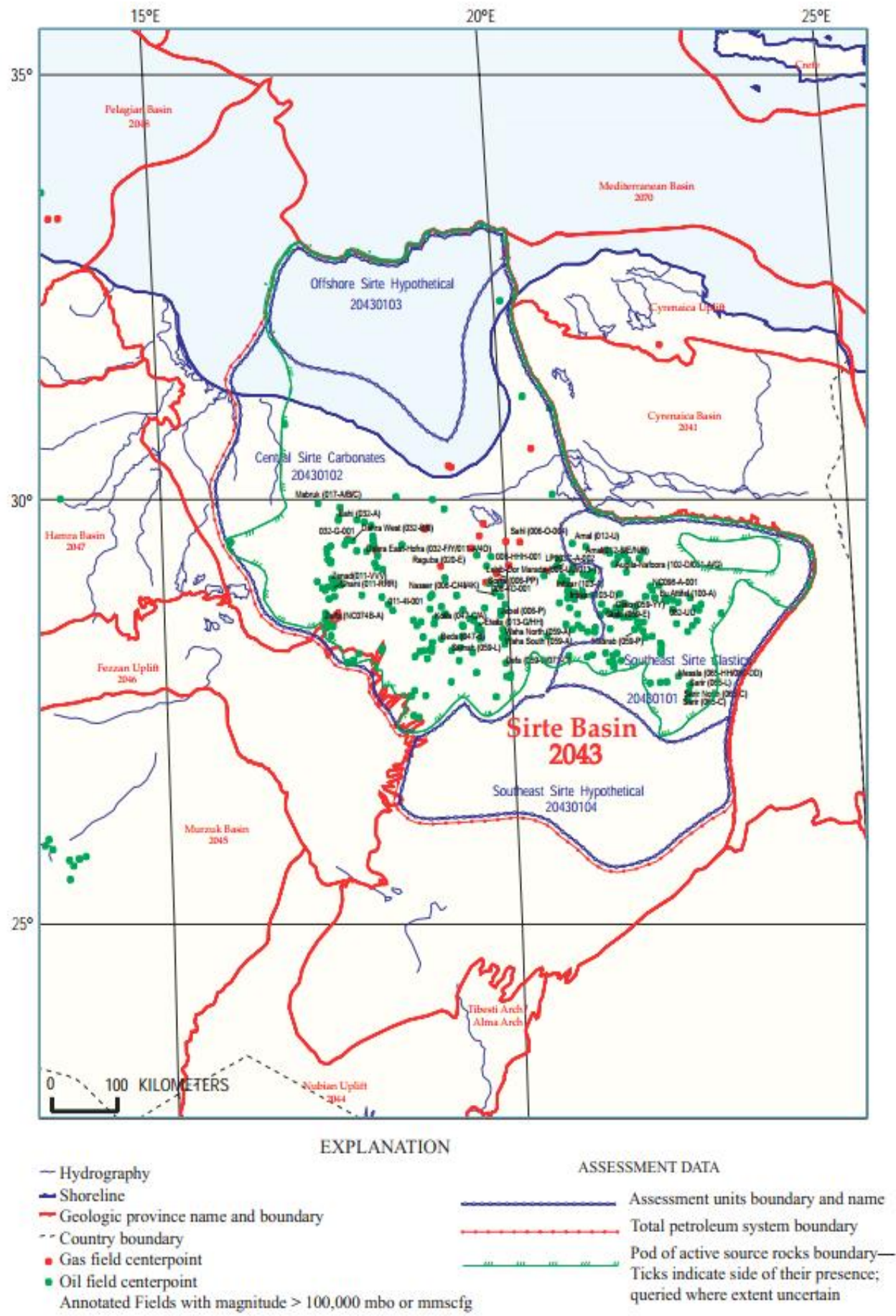

Figure 1. The Sirte Basin is a Libyan oilfield [13] 


\subsection{Decline Curve Analysis (DCA)}

Arps (1945) [14] proposed the curvature in the production rare versus time. The method can be described by doing a plot of oil or gas production data rate versus time that could be extrapolated to provide an estimate of future rate of production for a well or a field. With this forecasting, it is possible to determine the EUR of the well or the field. However, the basic assumption in the DCA is that the parameters controlling the decline trend of the curve in the past will continue to govern the trend in the future in a uniform manner. However, the normal shape of the decline curve effected by several factors: (1) Human factors, such as restricted production rate to the allowable rate setup by regulatory body, marketing, or due to shutting down of wells for well testing, workover, etc. (2) Production conditions, such as changing the number of producers, changing the lift conditions, changing the productivity index due to permeability changing around the wellbore, and changing the surface conditions. (3) Reservoir factors, such as reservoir drive mechanism, reservoir rock and fluid properties, relative permeability curves and using of water injection, water flooding and EOR techniques.

DCA uses empirical equations that models how the flow rate changes with time assuming a certain decline rate. It is one of the most used forms of data analysis to evaluate gas and oil reserves and predict future production. This technique is based on the assumption that past production trends and their control factors will continue in the future and; therefore, can be extrapolated and described by one of the three mathematical expressions; (1) Exponential decline (2) Harmonic decline and (3) Hyperbolic decline. A major assumption here is that the most dominant past behavior will govern the future behavior of the well's performance. Obviously, this is not necessarily true but works in many cases. It could also yield reasonable results when more wells are lumped together. However, this technique ignores any geological information from the field and, therefore, could give very unreasonable results in some cases.

There are some factors that affect the trend of production decline. the main factors may include; (1) Human factors (such as the restriction of the production rate to the allowable rate setup by the regulatory body, restriction due to the marketing or shutting down of wells for well testing), (2) production conditions (such as changing number of producers, changing lifting conditions, changing the productivity index of the well due to acidification, damage, hydraulic fracturing or re-perforations), or Change surface conditions (such as changing the well head pressure or separator pressure), and (3) reservoir factors (such as reservoir drive mechanisms, reservoir fluid and rock properties or the use of pressure maintenance, waterflooding and EOR techniques). Equation 5 presents the general form for decline curve analysis, and Equation 6 presents the cumulative production formula. However, exponential $(b=0)$ and harmonic $(b=1)$ decline are special cases of these formulas.

$q=\frac{q_{i}}{(1+D b t)^{1 / b}}$

$N_{p}=\frac{q_{t}^{b}}{D(1-b)}\left[q_{i}^{1-b}-q^{1-b}\right]$

Variables;

$q=$ Current production rate;

$q_{i}=$ Initial production rate (start of production);

$D=$ Initial nominal decline rate at $t=0$;

$t=$ Cumulative time since start of production;

$b=$ Decline constant normally has a value $0<b<1$;

$N_{p}=$ Cumulative production being analyzed .

The exponential decline curve technique uses a semi log plot of $q$ versus $t$. In general, this plot provides a linear trend, which can be extrapolated to any future time or a desired economic production limit. The corresponding value of $\mathrm{Np}$ can be estimated from that extrapolation. The governing equation for the case of the exponential production decline is given by Equation 7.

$q_{o}=q_{i} e^{-D t}$

From Equation 7, a rate-cumulative production relationship can be developed. The definition of cumulative production is given by:

$N p=\int_{0}^{t} q_{o} d t$

Substituting Equation 7 into Equation 8 and integrating yields:

$N p=\int_{0}^{t} q_{i} e^{-D t} d t=\frac{1}{D}\left\{q_{i}-q_{i} e^{-D t}\right\}$ 
Substituting Equation 8 into the last part of Equation 9 yields:

$N p=\frac{1}{D}\left(q_{i}-q_{o}\right)$

Equation 10 can be used to obtain the EUR by using the data obtained from the plot of $q_{o}$ versus $t$ and at a desired economic production limit. In addition, by solving Equation 10 for $q_{o}$ the rate-cumulative production relationship can be obtained as in Equation 10.

$q_{o}=q_{i}-D N p$

\section{$\log \left(q_{o}\right)$ versus Production Time, $t$}

The three oil wells were found to be declining exponentially $(b=0)$, and their rate time performances are presented in Figures 2 to 4. Most of the plots presented a linear trend, and the value of the EUR is obtained at $q_{o}$ value of 100 bpd. The results are summarized in Table 1.

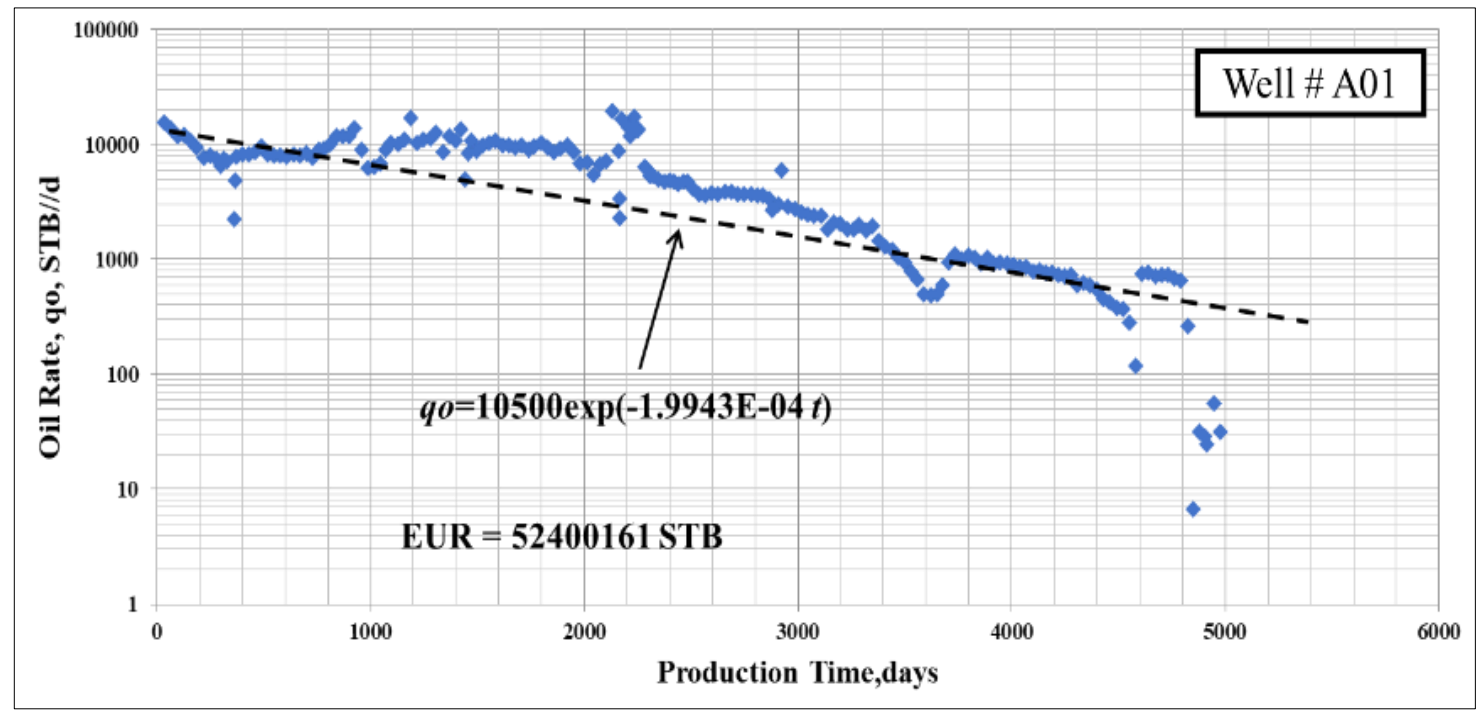

Figure 2. Oil production rate versus production time for well A01

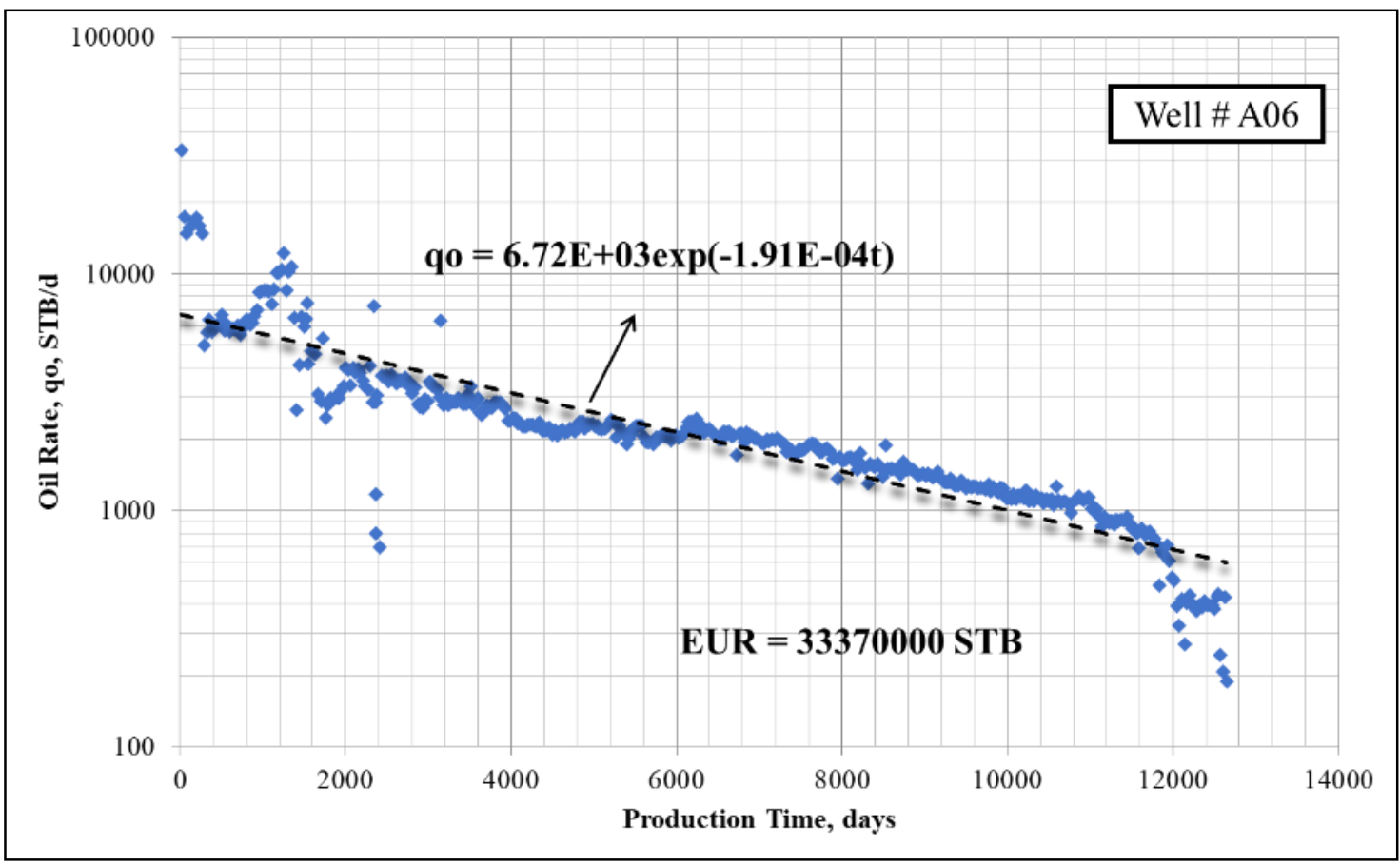

Figure 3. Oil production rate versus production time for well A06 
$\log \left(q_{o}\right)$ versus Production Time, $t$

Table 1. EUR from $\log \left(q_{o}\right)$ vs. production time, $t$

\begin{tabular}{cccc}
\hline Well & Straight-line Eq. & Decline rate, $\boldsymbol{D}$ & EUR \\
\hline A01 & $q o=10500 \exp (-1.9943 \mathrm{E}-04 t)$ & $0.0728 /$ year & 52.40MM STB \\
A06 & $q_{o}=6.72 \mathrm{E}+03 \exp (-1.91 \mathrm{E}-04 t)$ & $0.0697 /$ year & $33.37 \mathrm{MM} \mathrm{STB}$ \\
A28 & $q_{o}=3.48 \mathrm{E}+03 \exp (-2.754 \mathrm{E}-04 t)$ & $0.1005 /$ year & $12.45 \mathrm{MM} \mathrm{STB}$ \\
\hline
\end{tabular}

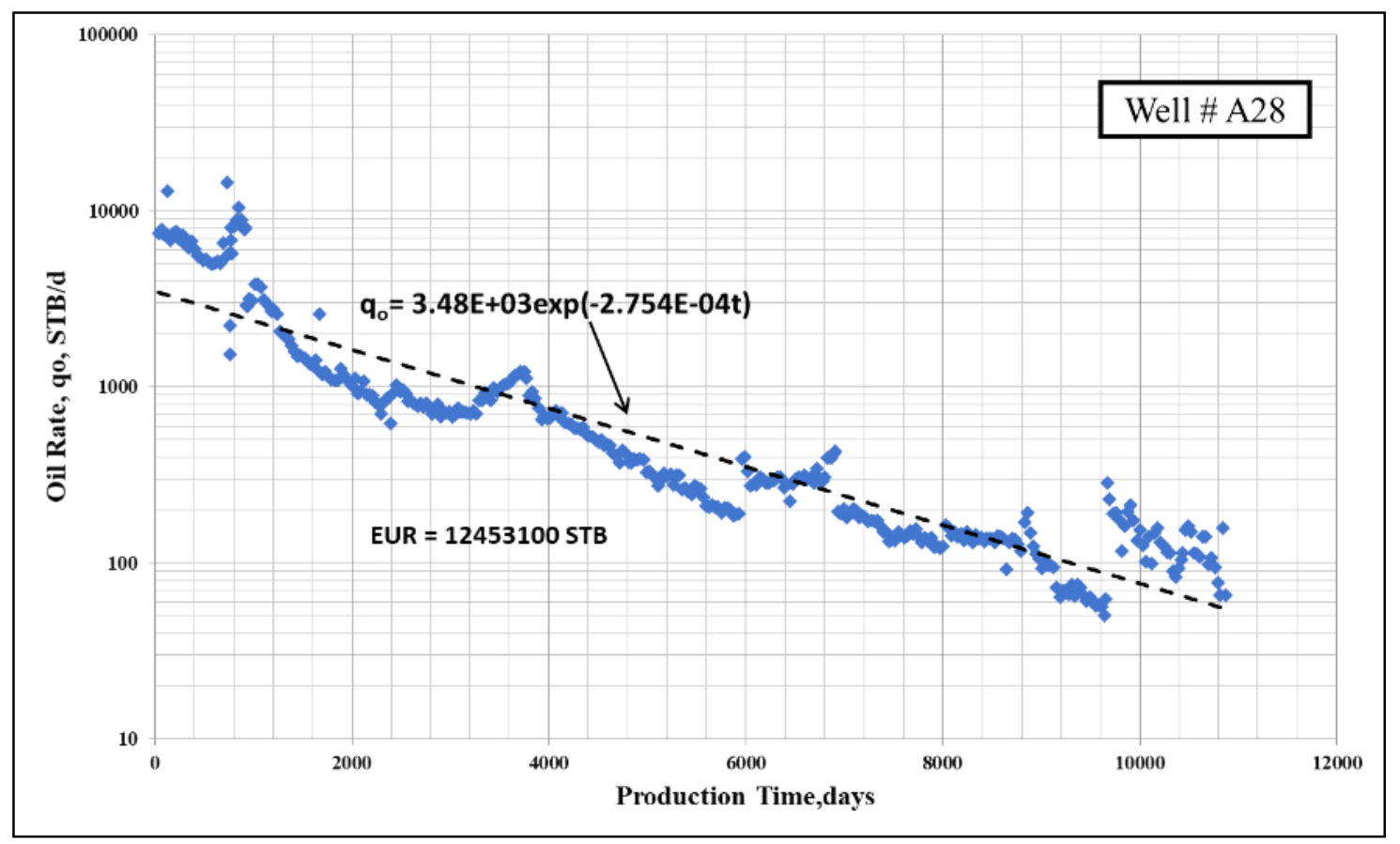

Figure 4. Oil production rate versus production time for well A28

Oil Production Rate, $q_{o}$ versus Cumulative Oil Production, $N_{p}$

The plots of $q_{o}$ vs $N_{p}$ for A01, A06 and A28 are presented in the Figures 5 to 7 respectively. The values of the EUR for each well are evaluated at $q_{o}$ value of $100 \mathrm{bpd}$. Table 2 illustrated the results of EUR of the wells.

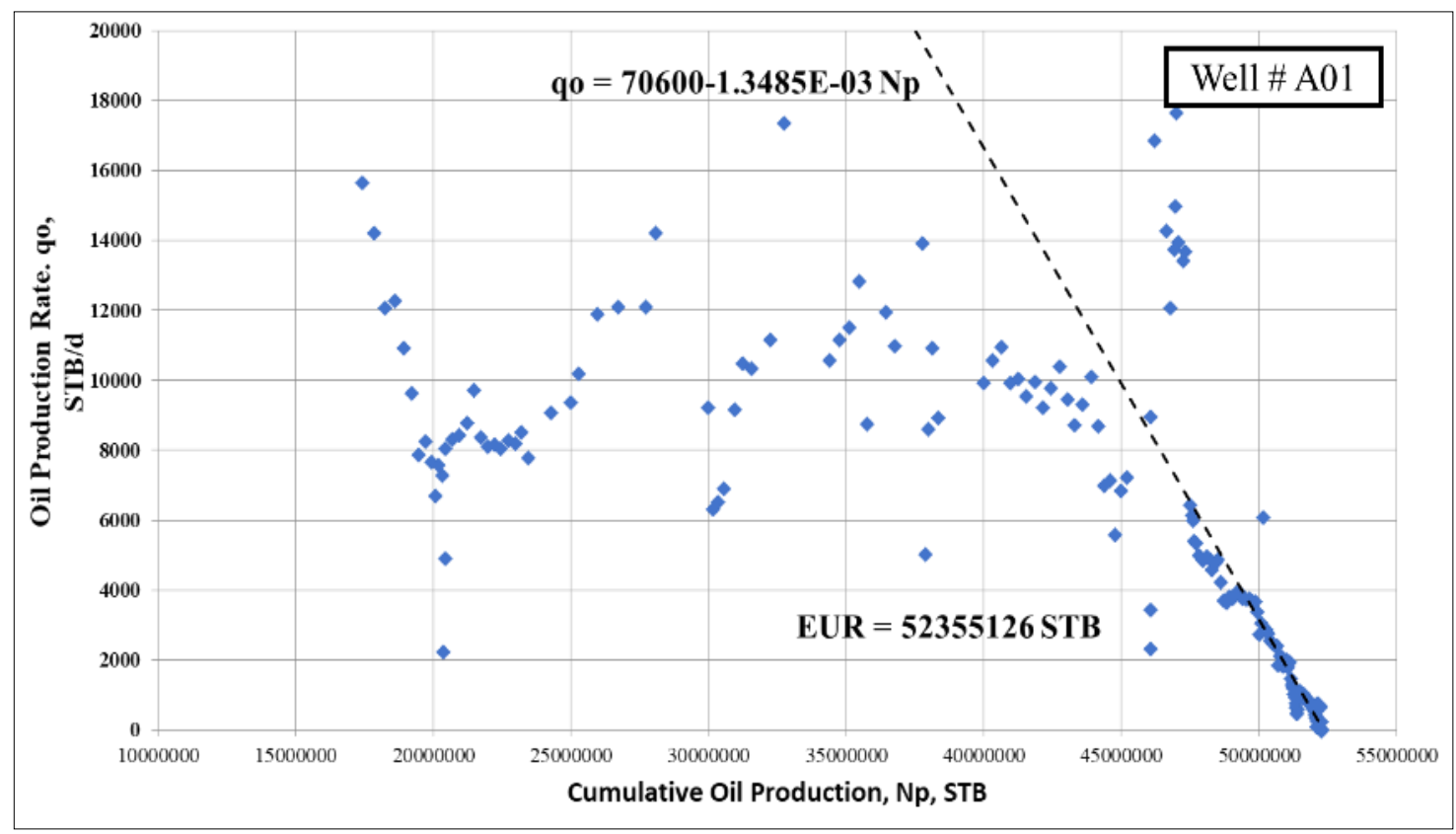

Figure 5. Oil production rate versus cumulative oil production for well A01 


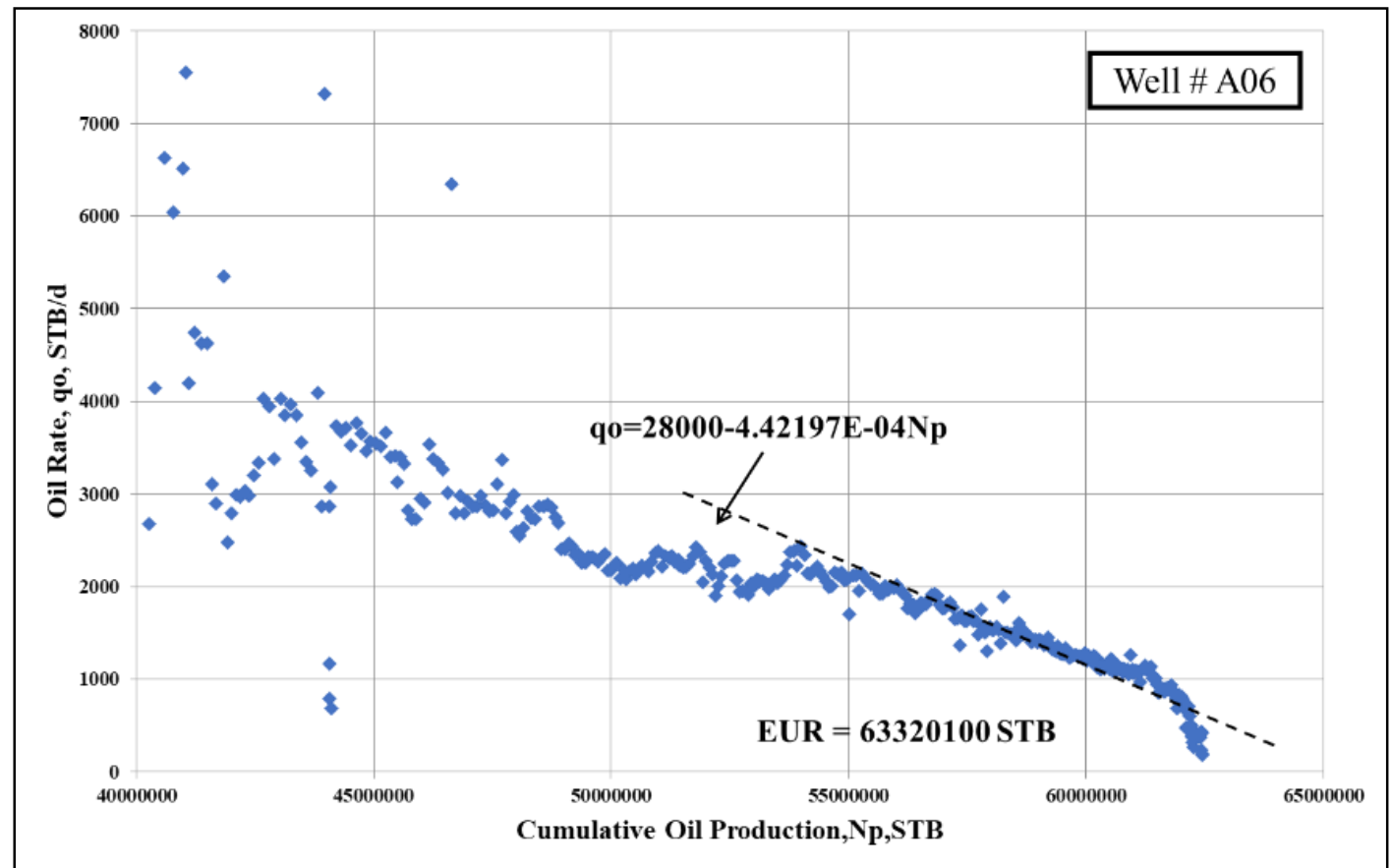

Figure 6. Oil production rate versus cumulative oil production for well A06

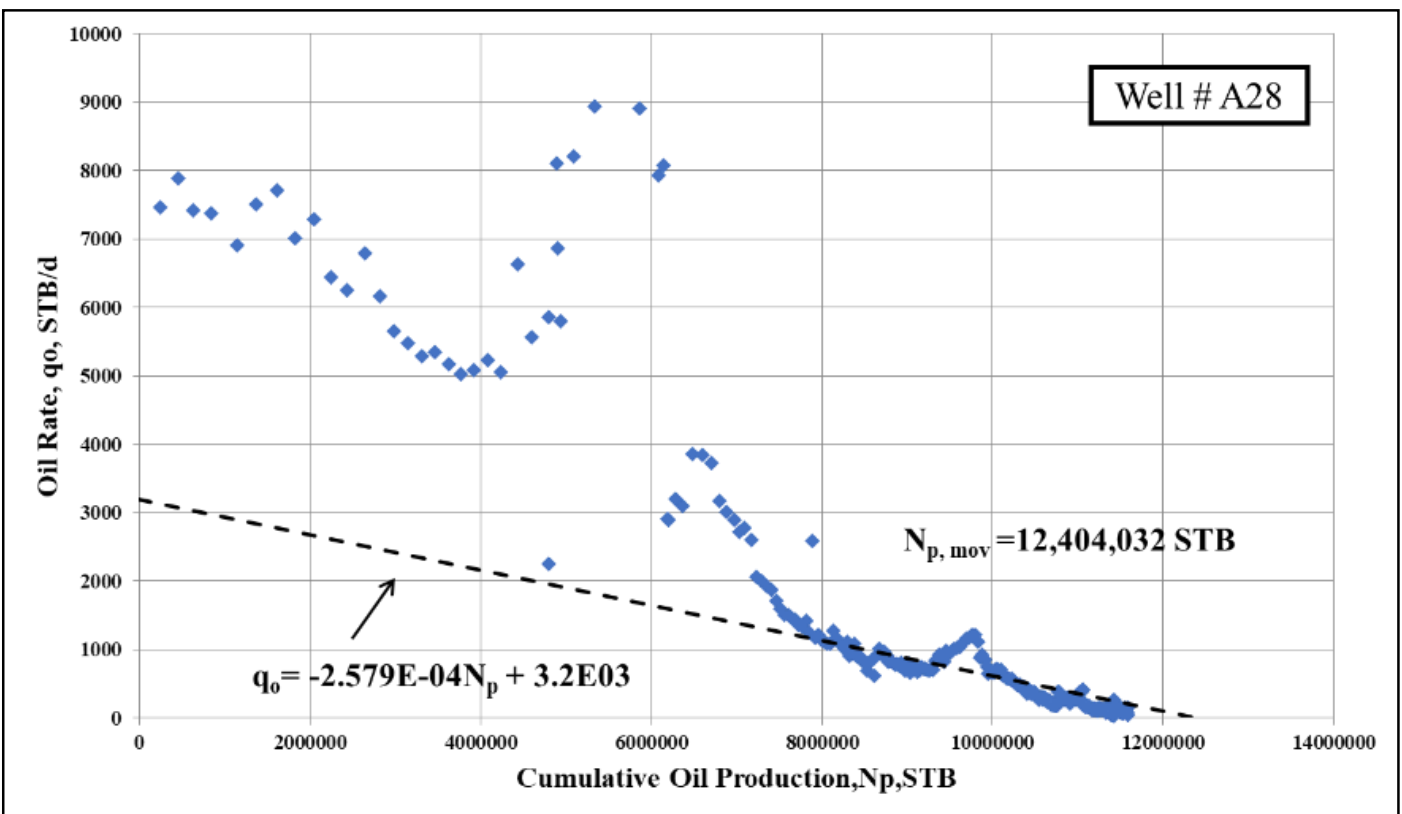

Figure 7. Oil production rate versus cumulative oil production for well A28

Reciprocal of oil rate, $1 / q_{o}$ versus oil material balance time, $t_{o}$

Bondar and Blasingame (2002) [15] and Blasingame and Reese (2007) [16] applied a reciprocal rate method to estimate EUR. The approach required a plot of the reciprocal flowrate $(1 / q)$ and material balance time, $t_{o},\left(N_{p} / q\right)$ assuming a constant flowing bottom-hole pressure $\left(p_{w f}\right)$, which has the following relation:

$\frac{1}{q}=c+m\left[\frac{N_{p}}{q}\right]$

In contrast, the plot $1 / q$ versus $t_{o}$ yields a straight line with slop of $m=1 /$ EUR. Nonetheless, Blasingame and Reese (2007) [16] shown that the method should tolerate arbitrary changes in $p_{w f}$ particularly smooth changes. They, also, noticed that this approach has proven to be robust and consistent, likewise, it can be applied in all cases for oil and gas wells and it is more rigorous than Arps approch. Figures 8 to 10 illustrated the reciprocal of oil rate. The plots yield a linear trend for all the time period. 


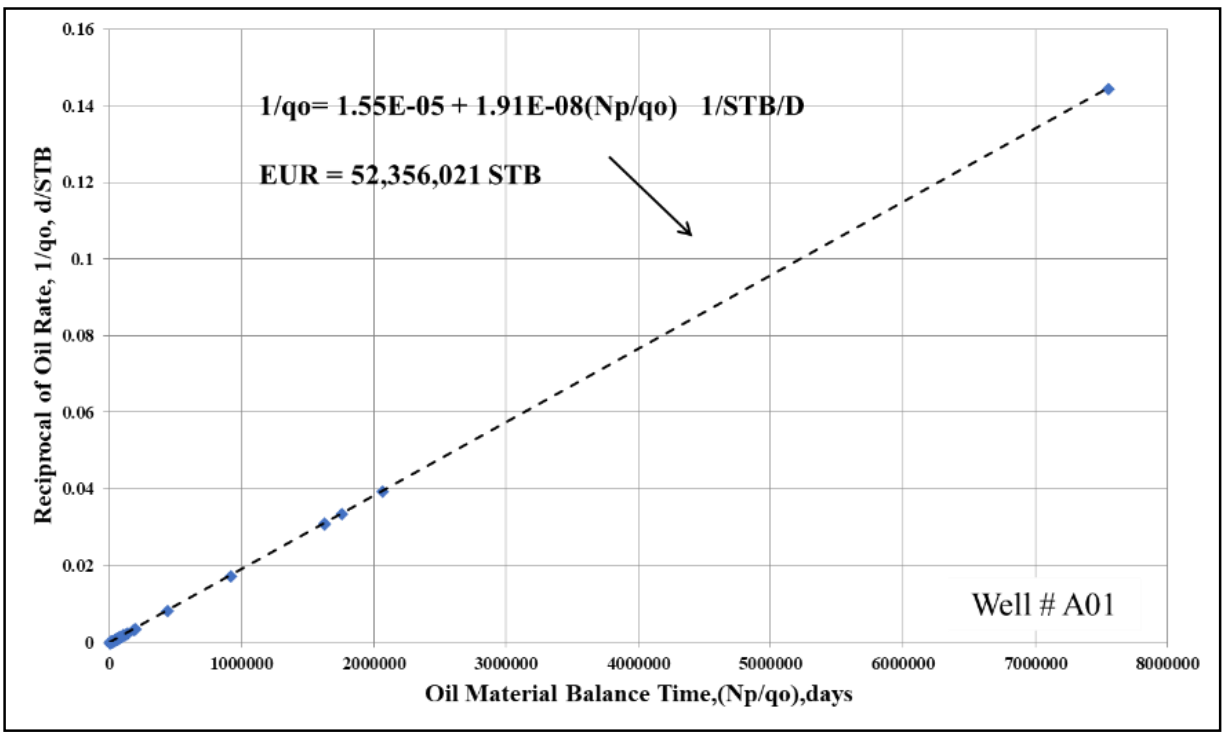

Figure 8. Reciprocal of oil rate, $1 / q_{o}$ versus oil material balance time, to for well A01

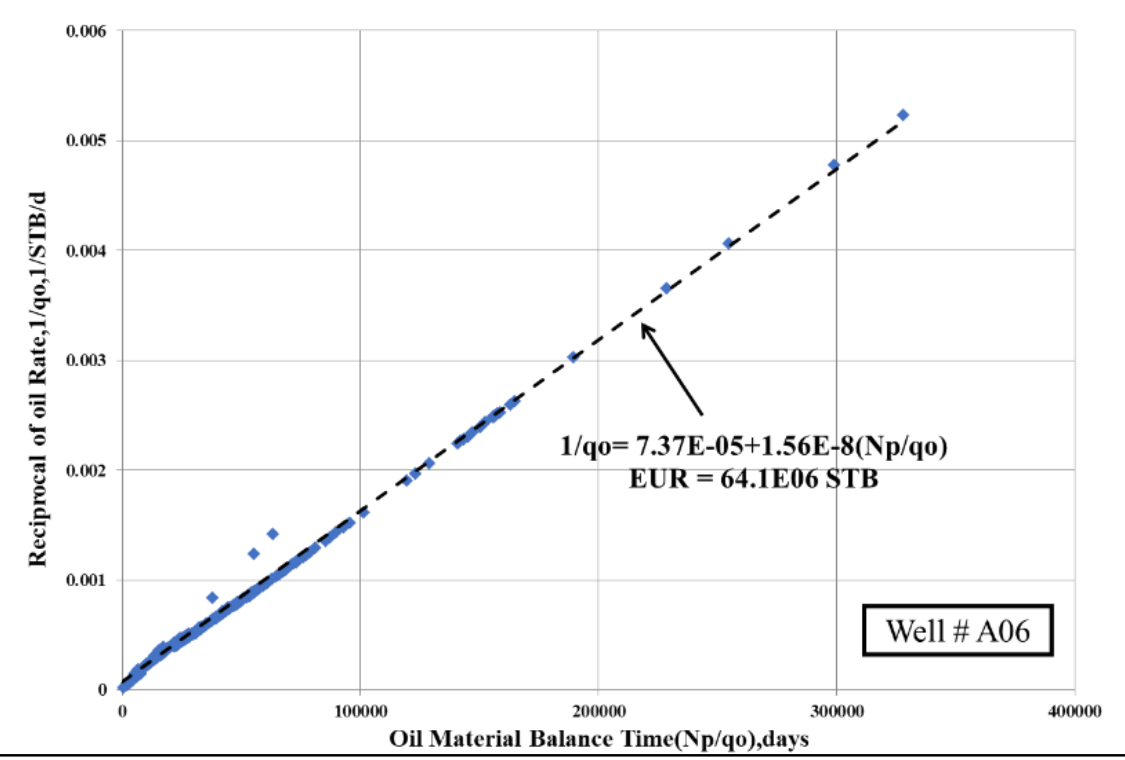

Figure 9. Reciprocal of oil rate, $1 / q_{o}$ versus oil material balance time, to for well A06

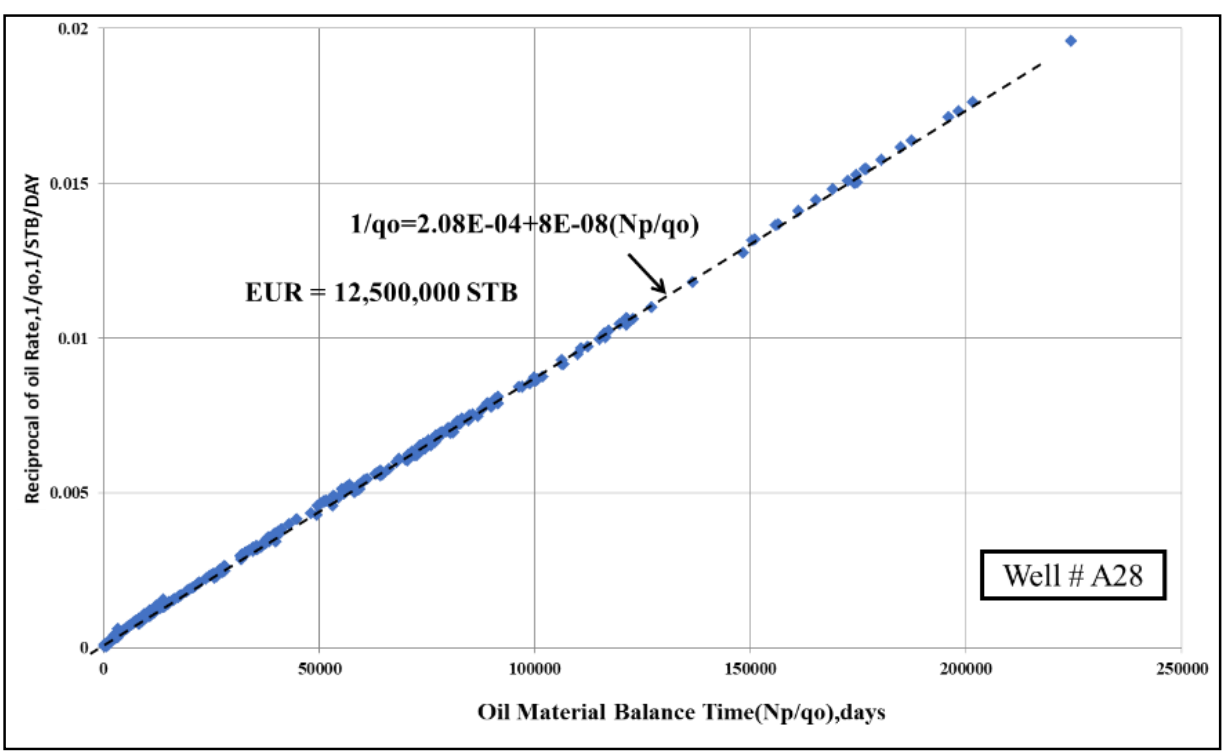

Figure 10. Reciprocal of oil rate, $1 / q_{o}$ versus oil material balance time, to for well A28 
Table 3. EUR from reciprocal of oil rate versus oil material balance time

\begin{tabular}{ccc}
\hline Well & Straight-line Eq. & EUR \\
\hline A01 & $1 / q_{o}=1.55 \mathrm{E}-05+1.91 \mathrm{E}-08 t_{o}$ & $52.36 \mathrm{MM} \mathrm{STB}$ \\
A06 & $1 / q_{o}=7.37 \mathrm{E}-05+1.56 \mathrm{E}-8 t_{o}$ & $64.10 \mathrm{MM} \mathrm{STB}$ \\
A28 & $1 / q_{o}=2.08 \mathrm{E}-04+8 \mathrm{E}-08 t_{o}$ & $12.50 \mathrm{MM} \mathrm{STB}$ \\
\hline
\end{tabular}

\subsection{Semi-steady State WOR Extrapolated Method}

The analysis and interpretation of the oil and water production data (WOR, $f_{w}$, and $f_{o}$ functions) take into consideration presence of both the oil and water phases flowing simultaneously in the reservoir. In 1990, Lo et al. [17] suggested using $\log (\mathrm{WOR})$ versus $N_{p}$ to obtain the EUR. They, also, investigated the dependence of the WOR versus $N_{p}$ plot on different well and reservoir characteristics. The results establish that the slop of the straight-line trend effected by conducting numerical simulations in 2D and 3D systems and by investigation various effects. They concluded that a linear relationship between the $\log (\mathrm{WOR})$ and $N_{p}$ adequately fit many of their results. However, it is important to bear in mind that this type of plot $\left(\log\right.$ WOR versus $N_{p}$ ) cannot be used to directly estimate the value of the EUR as needs some core data.

Chan (1995) [18] used numerical simulation to examine the sensitivity of WOR versus time on various of reservoir and production factors. He conjectured that a log-log plot of the curve can be used to diagnose the origin of the water production. Motivated by Chan's work, Yorsos et al. in 1999 provided a fundamental investigated by conducting analytical and numerical studies of waterflooding under variety of condition to analyze the behavior of WOR curves in various time domains. They concluded that the relationship between the WOR and time contains two effects, one due to the relative permeability and mobility and the other due to the production geometry.

Bondar and Blasingame (2002) [15] discussed various straight-line methods for the WOR functions in various forms $\left(\log \mathrm{WOR}, \log f_{w}\right.$, and $f_{o}$ ) versus the $N_{p}$. They, also, proposed two straight-line trend plots to estimate the EUR; $1 / f_{w}$ versus $N_{p}$, and $1 / q_{o}$ versus $N_{p} / q_{o}$. The plot of $1 / f_{w}$ versus $N_{p}$ yields an apparent linear trend that can be extrapolated to provide an estimate of EUR.

To reduce the uncertainty of EUR three analysis plots are applied here for WOR extrapolated method; (1) $\log \left(f_{w}\right)$ versus $\mathrm{Np}$ (2) $f_{o}$ versus $N_{p}$, and (3) $1 / f_{w}$ versus $N_{p}$. All the plots, however, show a linear trend at late-time WOR behavior when the value of $f_{w}$ function approaches $0.5(\mathrm{WC}=50 \%)$ or higher. Consequently, the plots can estimate the value of the mobile oil (EUR) by extrapolating the WOR linear trend to an economic limit of the WOR function, which in this study was selected to be at $99 \%$ WC. Typically, the plots show a high degree of scatter in the earliest production data, which could be due to the realization that these data represent transient or transition flow behavior.

$\log \left(f_{w}\right)$ Versus $N_{p}$

Figures 11 to 13 show the plot of $\log \left(f_{w}\right)$ versus $N_{p}$. Obviously, the semi-steady State WOR period produced a straight-line which extrapolated to WC $99 \%$ as an economic limit. The results are summarized in Table 4.

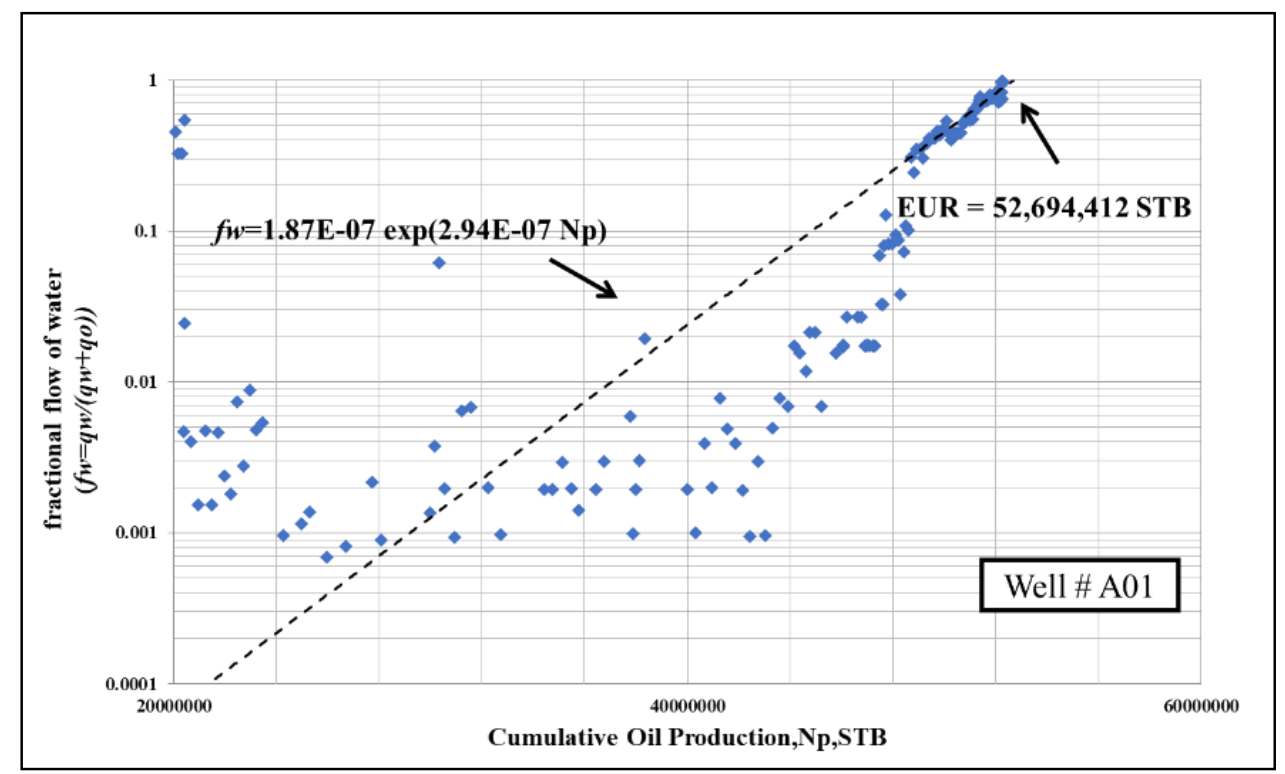

Figure 11. Fractional flow of water versus cumulative oil production for well A01 


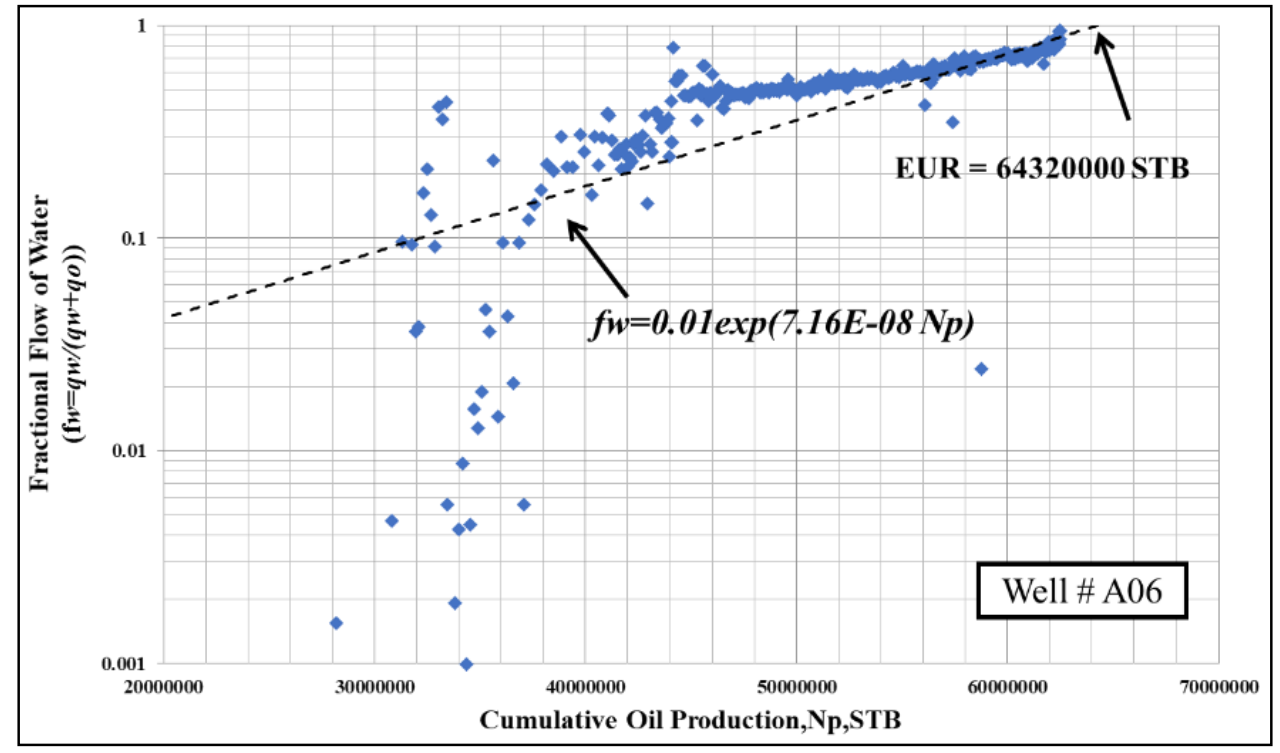

Figure 12. Fractional flow of water versus cumulative oil production for well A06

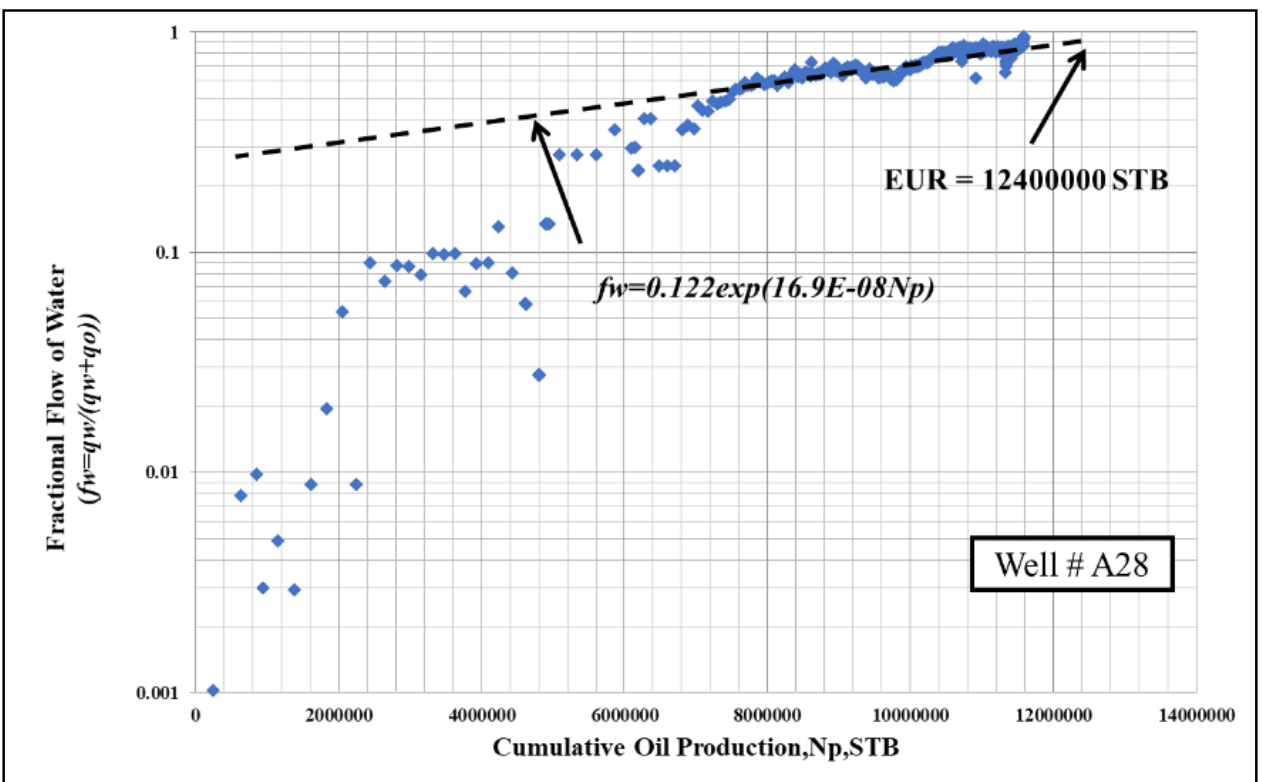

Figure 13. Fractional flow of water versus cumulative oil production for well A28

Table 4. EUR from $\log \left(f_{w}\right)$ versus $N_{p}$

\begin{tabular}{ccc}
\hline Well & Straight-line Eq. & EUR \\
\hline A01 & $f_{w}=1.87 \mathrm{E}-07 \exp \left(2.94 \mathrm{E}-07 N_{p}\right)$ & $52.67 \mathrm{MM} \mathrm{STB}$ \\
A06 & $f_{\mathrm{w}}=0.01 \exp \left(7.16 \mathrm{E}-08 N_{p}\right)$ & $64.32 \mathrm{MM} \mathrm{STB}$ \\
A28 & $f_{w}=0.122 \exp \left(16.9 \mathrm{E}-08 N_{p}\right)$ & $12.40 \mathrm{MM} \mathrm{STB}$ \\
\hline
\end{tabular}

$f_{o} \operatorname{Versus} N_{p}$

Figures 14 to 16 show the plot of $f_{o}$ versus $N_{p}$. The late datapoints (semi-steady state) formed a straight-line trend. This straight line was extrapolated to an economic limit of $99 \% \mathrm{WC}$ in order to obtain the EUR and summarized in Table 5 .

Table 5. EUR from $f_{o}$ versus $N_{p}$

\begin{tabular}{ccc}
\hline Well & Straight-line Eq. & EUR \\
\hline A01 & $f_{o}=12-2.28522 \mathrm{E}-07 N_{p}$ & $52.51 \mathrm{MM} \mathrm{STB}$ \\
A06 & $f_{o}=8.5-1.3381 \mathrm{E}-07 N_{p}$ & $63.52 \mathrm{MM} \mathrm{STB}$ \\
A28 & $f_{o}=1.20-9.35 \mathrm{E}-08 N_{p}$ & $12.80 \mathrm{MM} \mathrm{STB}$ \\
\hline
\end{tabular}




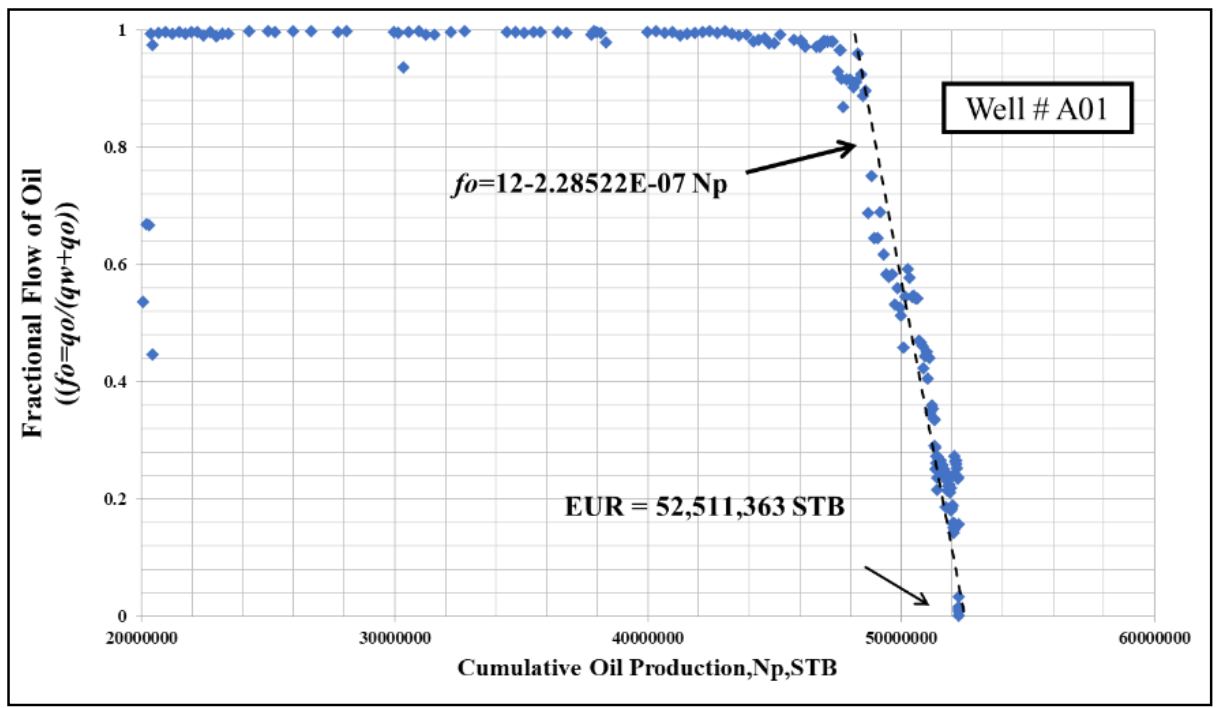

Figure 14. Fractional flow of oil versus cumulative oil production for well A01

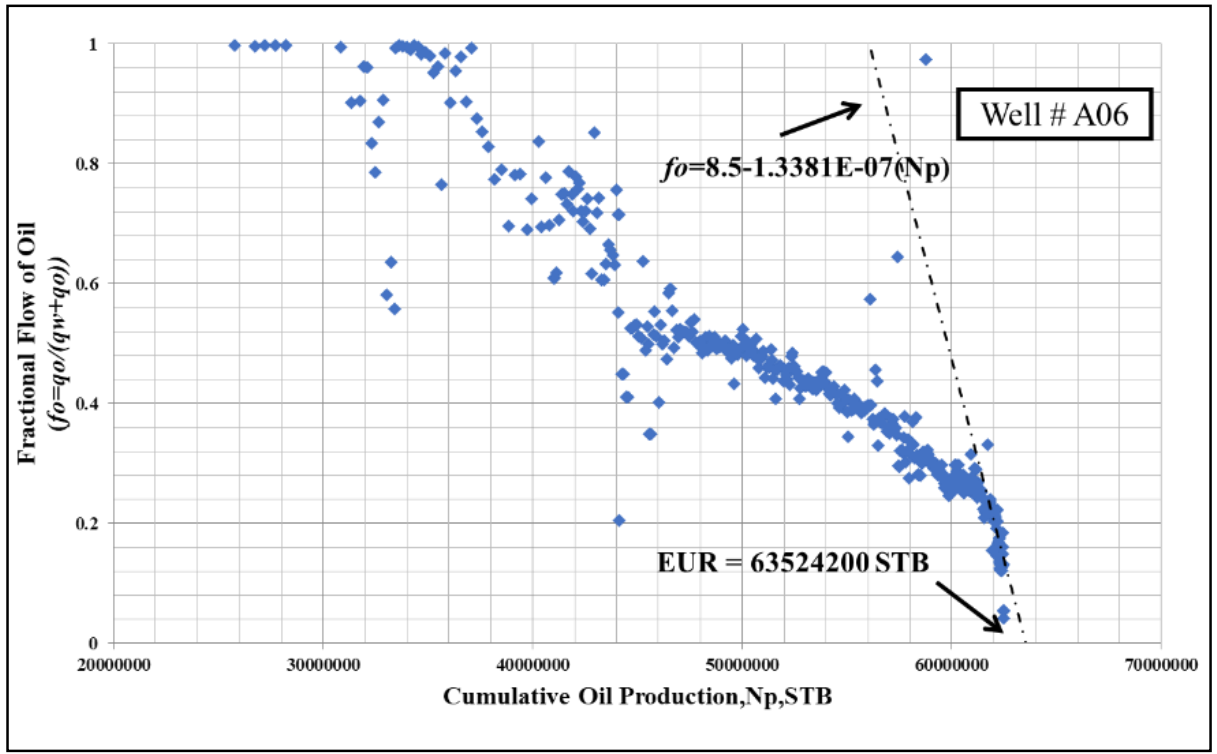

Figure 15. Fractional flow of oil versus cumulative oil production for well A06

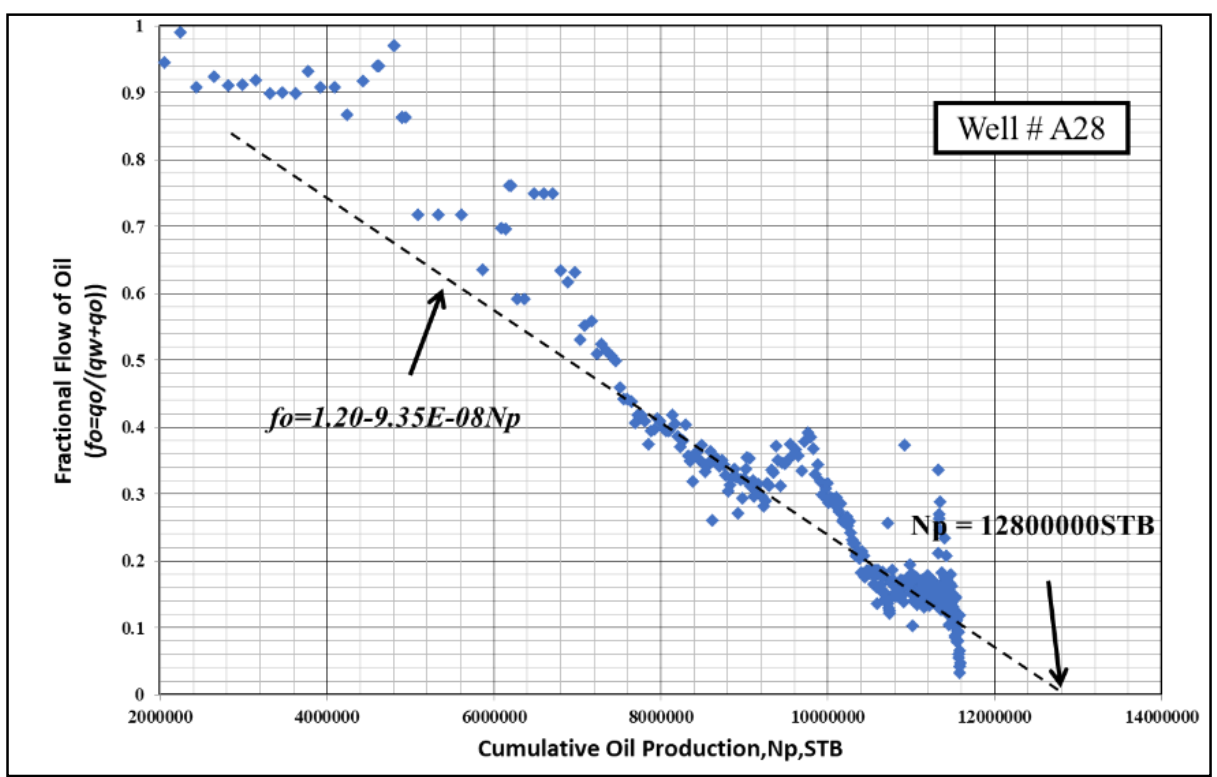

Figure 16. Fractional flow of oil versus cumulative oil production for well A28 


\section{$1 / f_{w}$ Versus $N_{p}$}

The Figures 17 to 19 show the semi-state state of $f_{w}$ vs $N_{p}$ extraplotated technique of the well A01, A06 and A28 respectively. The Figures show linear trend of the late datapoints and the results EUR are tabolated in Table 6.

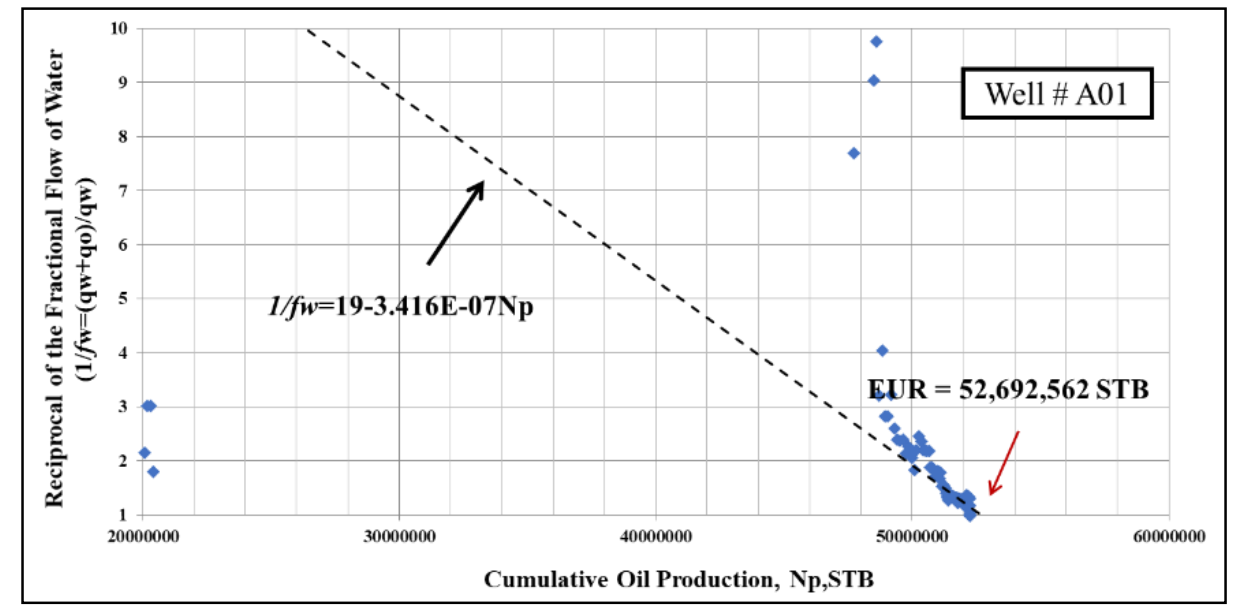

Figure 17. Reciprocal of fractional flow of water versus cumulative oil production for well A01

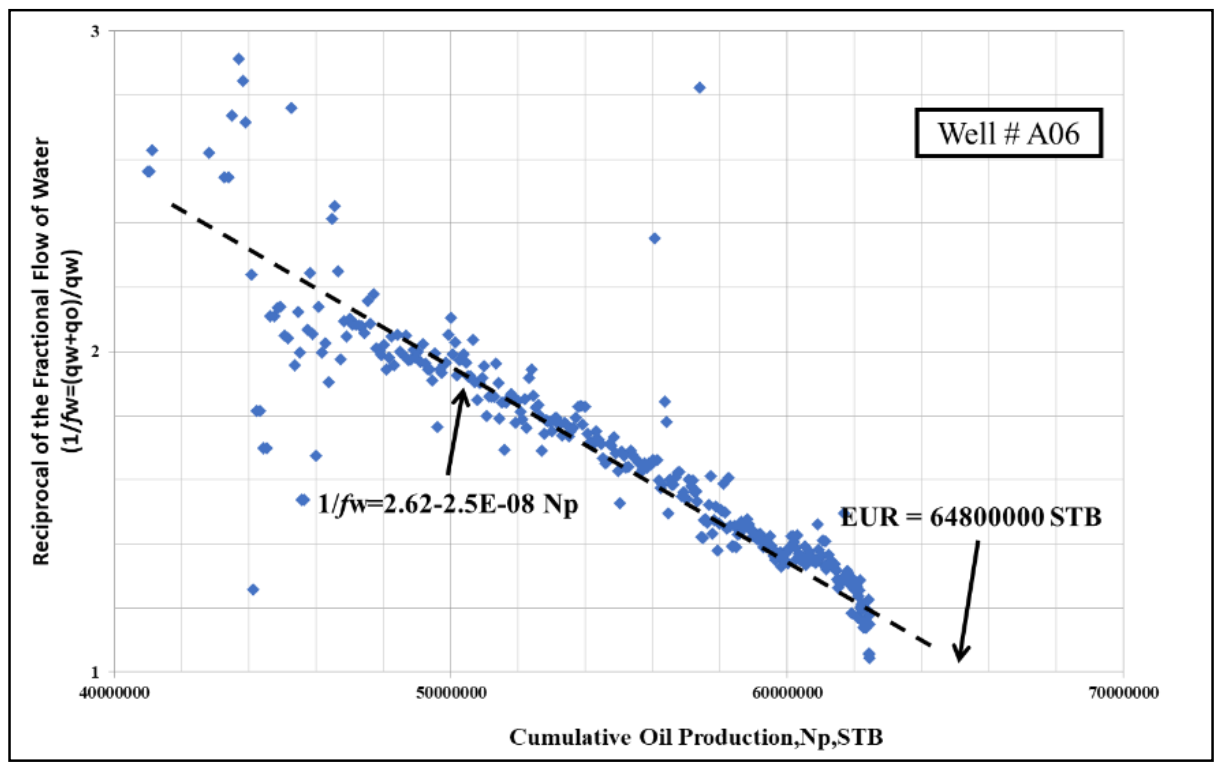

Figure 18. Reciprocal of fractional flow of water versus cumulative oil production for well A06

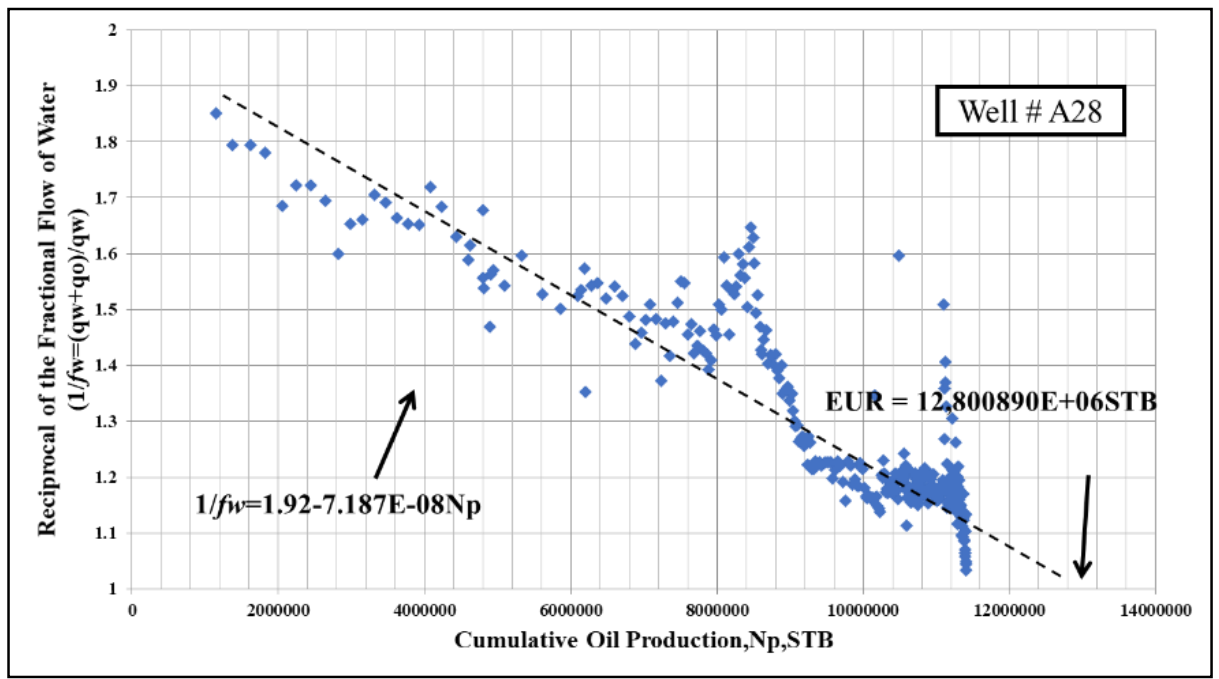

Figure 19. Reciprocal of fractional flow of water versus cumulative oil production for well A28 
Table 6. EUR from $1 / f_{w}$ versus $N_{p}$

\begin{tabular}{ccc}
\hline Well & Straight-line Eq. & EUR \\
\hline A01 & $1 / f_{w}=19-3.416 \mathrm{E}-07 N_{p}$ & $52.67 \mathrm{MM} \mathrm{STB}$ \\
A06 & $1 / / f_{w}=2.62-2.5 E-08 N_{p}$ & $64.80 \mathrm{MM} \mathrm{STB}$ \\
A28 & $1 / f_{w}=1.92-7.187 \mathrm{E}-08 N_{p}$ & $12.80 \mathrm{MM} \mathrm{STB}$ \\
\hline
\end{tabular}

\section{3. $X$-plot}

The $X$-plot technique is based on fractional flow and the Buckley-Leverett calculations. Based on Ershaghi \& Omorigie (1978). [19], an interesting application of the $X$-plot method is that the linear plot of $N_{p}$ versus $X$-function (Equation 12) gives a straight line that can be extrapolated to any desired WC (economic $f_{w}$ ) as a mechanism for determining the corresponding EUR. The extrapolation of the past performance on the plot is a complicated task. The difficulty arises mainly because a curve fitting by simple polynomial approximation does not result in satisfactory answers in most cases. Due to the fact that $X$-function has a parabolic shape the recommendation is to restrict this technique to $f_{w}$ greater than $50 \%$. Differentiating $X$-function with respect to $f_{w}$ and equating the first derivative to zero can prove this restriction. Ershaghi and Abdassah (1984) [20] provides a detailed explanation of this concept.

$x=\ln \left(\frac{1}{f_{w}}-1\right)-\frac{1}{f_{w}}$

Lijek (1989) [21] examined various WOR analysis techniques and presented analytical methods by which the oil rate can be modeled as a function of time. He examined the linearity of; WOR versus $N_{p}, X$-plot method, and $\frac{1}{W O R}+$ WOR versus cumulative water injection $\left(W_{i}\right)$.

Bondar and Blasingame (2002) [15] considered that the X-plot technique gave the least consistent results compared to the other methods used. straight-line extrapolation methods produced more consistent estimates of EUR than the Xplot technique. Also, they concluded that the X-function plot typically does not develop a clear straight-line trend. According, the logarithm of WOR, WC, or $f_{w}$ function plotted against $N_{p}$ is commonly used for evaluation and prediction of waterflood performance. This presumed semi-log plot of $f_{w}$ and oil recovery allows extrapolation of the straight line to any desired $f_{w}$ as a mechanism for determining the corresponding EUR. Straight line extrapolation method assumes that the mobility ratio is equal to unity and the plot of the log of relative permeability ratio of the lowing liquids, $\left(k_{r w} / k_{r o}\right)$, versus water saturation, $s_{w}$, is a straight line.

Yang (2009) [22] proposed two types of linear plots based on so-called $Y$-function (Equation 13 and 14); (1) plotting $Y$ versus $t_{D}$ on the $\log -\log$ scale gives a straight line trend with a slop of -1 and an intercept of $E_{V} / B$, and (2) plotting $Y$ versus reciprocal-of-time $\left(1 / t_{D}\right)$ is also a straight line with an intercipt of zero and a slop of $E_{V} / B$.

$Y=\left(\frac{E_{V}}{B}\right) \frac{1}{t_{D}}$

With the oil-fraction flow, $Y$ is defined as;

$Y=f_{o}\left(1-f_{o}\right)$

where $B$ is the relative permeability ratio parameter, and $E_{v}$ is the volumetric sweep efficincy. The parameter $t_{D}$ is the ratio of cumulative liquid production to the total pore volume $(P V)$ of the waterflood pattern area (swept and unswept). Yang indicated that forecasting can be performed with the historical-production data without needing to calculate parameter $E_{V}$ and $B$ or without the need of knowing reservir volume. Plotting $Y$ vesus $Q_{L}$ and $Y$ versus $1 / Q_{L}$ on $\log$-log scale yaldeis the features. Likewise, he showed that these plots can be applied to forecast the oil fraction flow and then to calculate the oil rate with known liquid rate. The analysis technique improve the reliability of EUR and production forecats. The $Y$-function method, as a performance diagnostic analysis method, can diagnose the production history for breakthrough timing. The flow regime diagram of the $Y$-function versus cumulative liquid production on the log-log scale are presented in Figure 20. A nearly constant $Y$-function value of 0.25 or slightly less is an indication of primary production behavior. When water breakthrough occurs, the $Y$-function starts to decline with slop of -1 (Yang, 2012) [23].

In a more recent study, Yang (2017) [24] declared that the waterflood analytical methods are obtained by solving 1D Buckly-Levertt equations [25] in the $X$-plot conditions. The dependent variable can be classified into two groups: cumulative production (oil, water, liquid or recovery factor) and water-cut feature variables. The water-cut feature variables can be various forms: $f_{w}, f_{o}$, WOR, $X$-plot function or $Y$-function. As well, he proposed analytical approach for $X$-plot method as follows: (1) use Y-function to confirm water breakthrough timing, to clarify possible impact or 
reconfiguration events, and to select a post-breakthrough reference point on the linear trend; (2) obtain cumulative liquid and oil $\left(Q_{L}, Q_{o}\right)$ and $f_{o}$ for the reference point; and (3) calculate the slop, $m$ of the straight-line trend and the $X$ value on the reference point, which will then solve for the intercept, $n$. When the parameters $m$ and $n$ are available, the $X$-plot method is used to predict the EUR. He concluded that the procedure of combining the $X$-plot method and $Y$ function method will reduce uncertainty in the EUR determination.

$X=\ln \left(\frac{1}{f_{w}}-1\right)-\frac{1}{f_{w}} ; n=\left(S_{w}-\frac{1}{B} \ln \frac{A}{M}\right) ; m=\frac{1}{B}$

Where $M$ is the mobility ratio, $B$ is a constant in the expression of the straight line in the semi-log oil to water relative permeability versus water saturation $\left(k_{r o} / k_{r w}=A e^{-B S_{w}}\right)$, and $A$ is a constant.

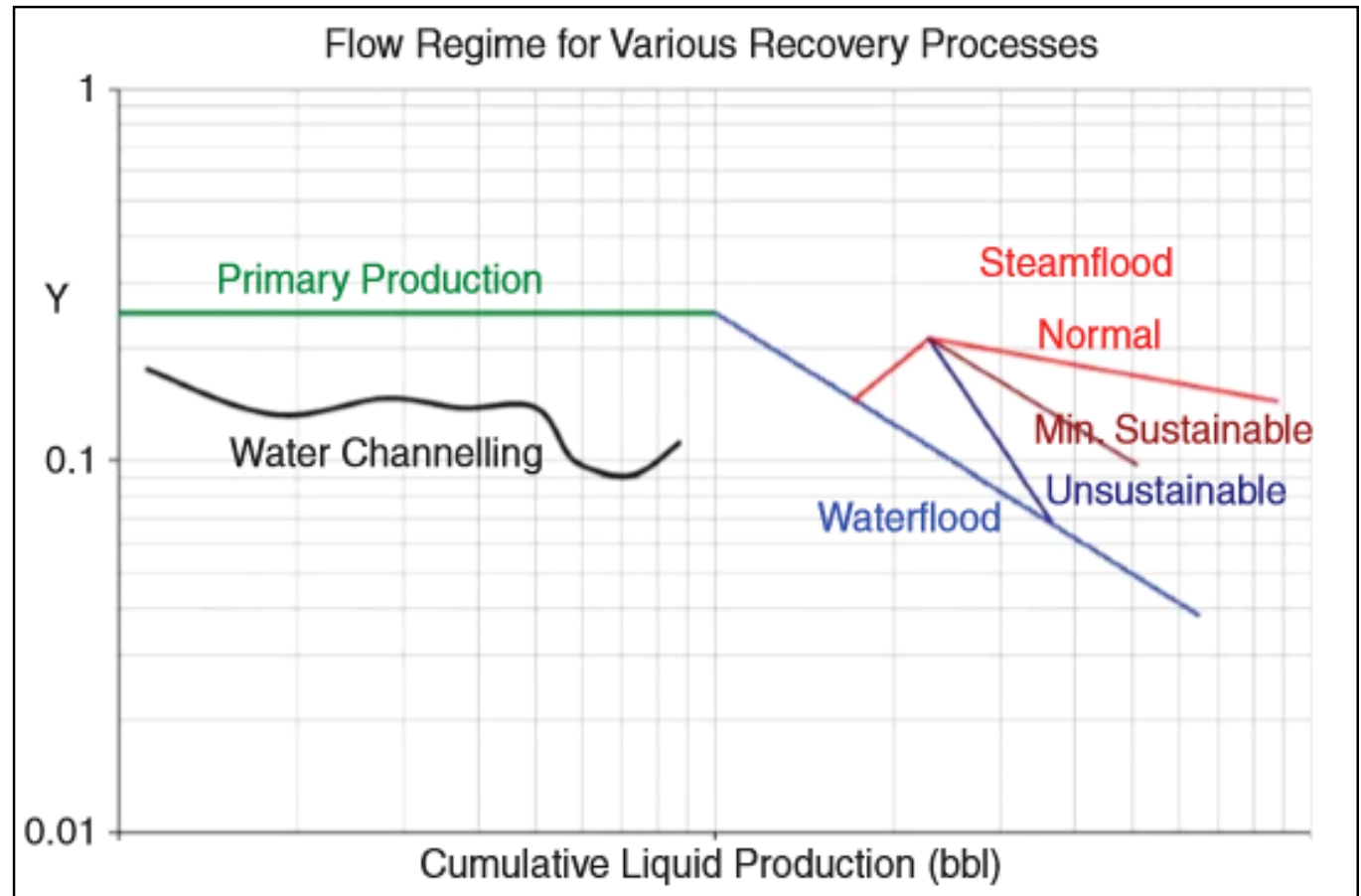

Figure 20. Flow-regime diagram for production surveillance

Bondar and Blasingame (2002) [15] mentioned that in all of the cases they considered, the X-plot technique gave the least consistent results compared to the other methods used. Contrary, Yang (2017) [24] reported that applying of X-plot method in analytical approach reduces uncertainty in the EUR determination. In this study the X-plot of the three oil wells show that the late datapoints formed a straight-line trend as described in Figures 21 to 23 . The assessment of EUR are illustrated in Table 7. .

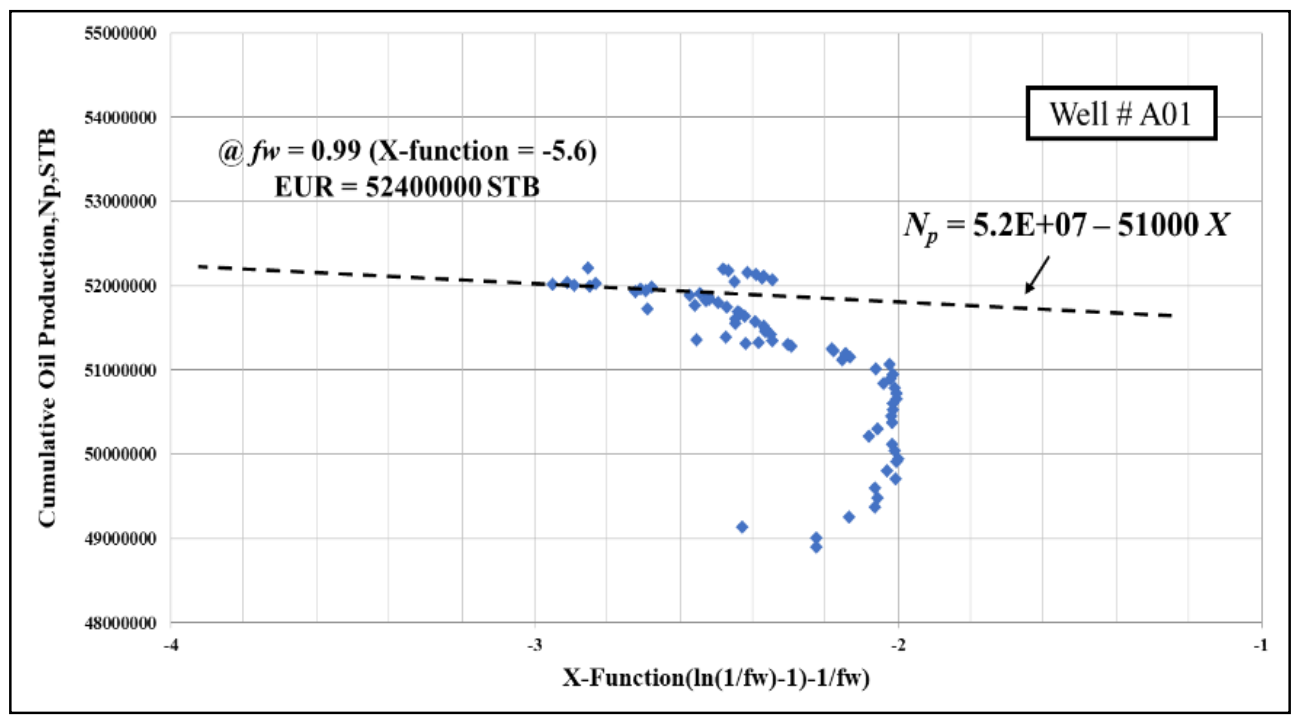

Figure 21. X-plot for well A01 


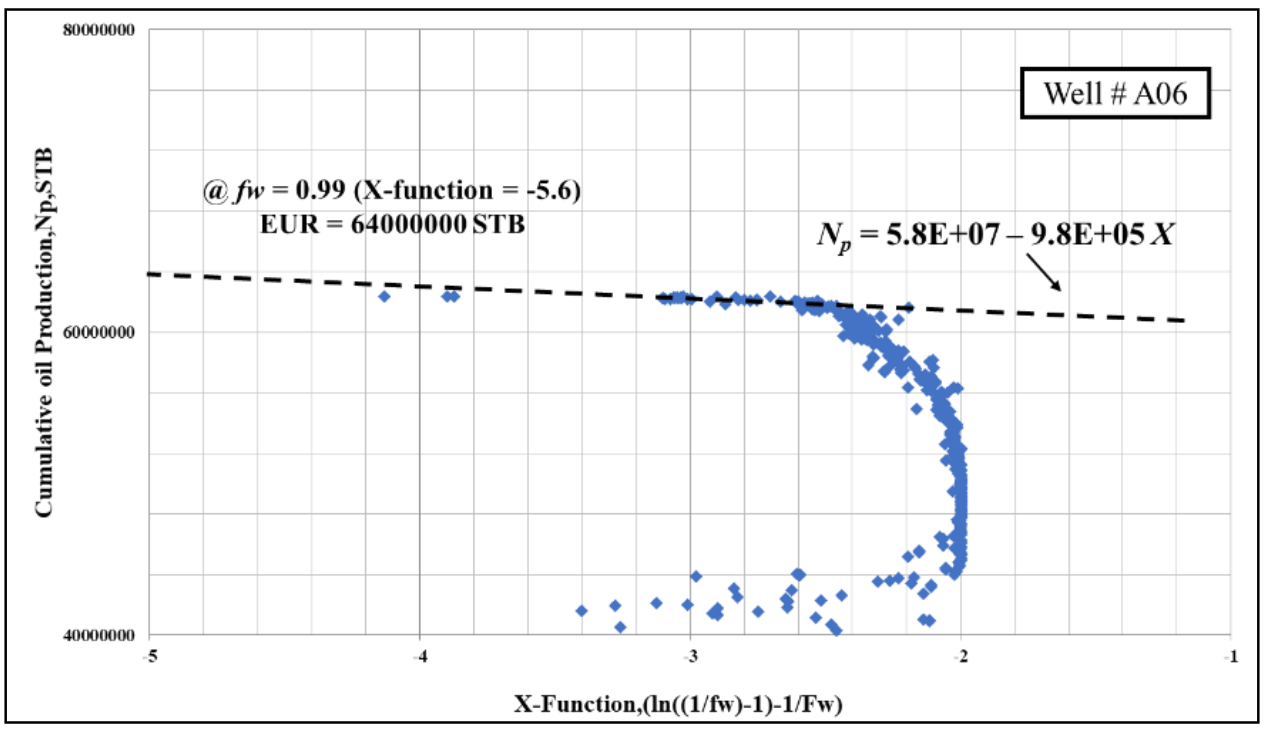

Figure 22. X-plot for well A06

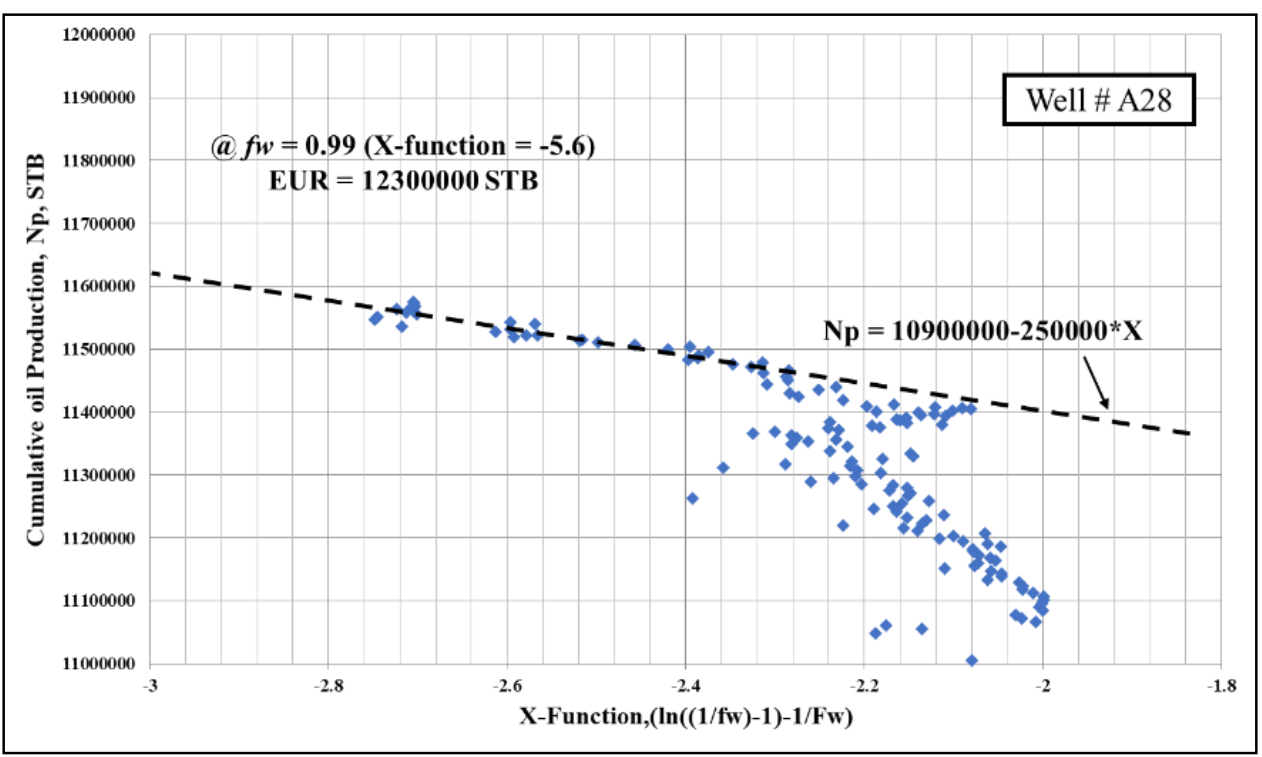

Figure 23. X-plot for well A28

Table 7. EUR from X-plot

\begin{tabular}{ccc}
\hline Well & Straight-line Eq. & EUR \\
\hline A01 & $N_{p}=5.2 \mathrm{E}+07-51000 X$ & $52.40 \mathrm{MM} \mathrm{STB}$ \\
A06 & $N_{p}=5.8 \mathrm{E}+07-9.8 \mathrm{E}+05 X$ & $64.00 \mathrm{MM} \mathrm{STB}$ \\
A28 & $N p=10900000-250000 X$ & $12.30 \mathrm{MM} \mathrm{STB}$ \\
\hline
\end{tabular}

\section{Conclusions}

Estimated ultimate recovery of oil and gas wells are required for evaluation and reservoir management purposes even though there is always uncertainty when making reserve estimates. Depending on the quantity and quality of the available data, different methods are used for the evaluation of the EUR. Employment of oil and water production data for reserve estimate have a certain degree of uncertainty; therefore, different methods should be applied to reduce this uncertainty. In fact, oil and water production data are regularly measured with time, which can be analyzed in a number of ways. The analysis and interpretation of the oil and water production data (WOR, $f_{w}$, and $f_{o}$ functions) take into consideration presence of both the oil and water phases flowing simultaneously in the reservoir. In particular, this paper provides verification and application of calculating the EUR from oil and water production data. The analysis consisted of performing plots of different OWR functions versus time or cumulative production that could be extrapolated to provide an estimate of future rate of production for a well or a field. The success of this method depends on our selection of straight line points. 
Three field examples from Libyan oilfield were analyzed with seven different extrapolation techniques:

- $\log \left(q_{o}\right)$ versus production time, $t$;

- $q_{o}$ versus $N_{p}$;

- $1 / q_{o}$ versus $t_{o}$

- $\log \left(f_{w}\right)$ versus $N_{p}$;

- $f_{o}$ versus $N_{p}$;

- $1 / f_{w}$ versus $N_{p}$, and;

- $N_{p}$ versus $X$-function.

These techniques should be applied simultaneously in order to obtain consistent approximate of the EUR. We believe that due to the uncertainty in the accuracy of these extrapolation methods and the lack of a fully rigorous mathematical basis, the best approach is to use as many extrapolation techniques as possible. This approach helps comparing the results obtained with different approaches providing consistency and a validation element. The results are summarized in Table 8 , illustrating reliable results.

Table 8. EUR Results

\begin{tabular}{ccccc}
\hline \multirow{2}{*}{ Method } & \multirow{2}{*}{ Plot } & \multicolumn{3}{c}{ EUR } \\
\cline { 3 - 5 } & & Well A01 & Well A06 & Well A28 \\
\hline \multirow{2}{*}{ DCA } & $\log \left(q_{o}\right)$ vs. $t$ & $52.40 \mathrm{MM}$ & $33.37 \mathrm{MM}$ & $12.45 \mathrm{MM}$ \\
& $q_{o}$ vs. $N_{p}$ & $52.36 \mathrm{MM}$ & $63.32 \mathrm{MM}$ & $12.40 \mathrm{MM}$ \\
& $1 / q_{o}$ vs. $t_{o}$ & $52.36 \mathrm{MM}$ & $64.10 \mathrm{MM}$ & $12.50 \mathrm{MM}$ \\
\hline \multirow{3}{*}{ Semi-steady State WOR } & $\log \left(f_{w}\right)$ vs. $N_{p}$ & $52.67 \mathrm{MM}$ & $64.32 \mathrm{MM}$ & $12.40 \mathrm{MM}$ \\
& $f_{o}$ vs. $N_{p}$ & $52.51 \mathrm{MM}$ & $63.52 \mathrm{MM}$ & $12.80 \mathrm{MM}$ \\
& $1 / f_{w}$ vs. $N_{p}$ & $52.67 \mathrm{MM}$ & $64.80 \mathrm{MM}$ & $12.80 \mathrm{MM}$ \\
\hline X-function & X-plot & $52.40 \mathrm{MM}$ & $64.00 \mathrm{MM}$ & $12.30 \mathrm{MM}$ \\
\hline
\end{tabular}

\section{Declarations}

\subsection{Author Contributions}

Conceptualization, S.K.E. and W.M.M.; methodology, W.M.M.; formal analysis, S.K.E. and W.M.M.; writingoriginal draft preparation, S.K.E. and W.M.M.; writing-review and editing, S.K.E. and W.M.M. All authors have read and agreed to the published version of the manuscript.

\subsection{Data Availability Statement}

Data sharing is not applicable due to a specific agreement with the company that provided the data.

\subsection{Funding}

The authors received no financial support for the research, authorship, and/or publication of this article.

\subsection{Declaration of Competing Interest}

The authors declare that they have no known competing financial interests or personal relationships that could have appeared to influence the work reported in this paper.

\section{References}

[1] Liu, Y.-Y., Ma, X.-H., Zhang, X.-W., Guo, W., Kang, L.-X., Yu, R.-Z., \& Sun, Y.-P. (2021). A deep-learning-based prediction method of the Estimated Ultimate Recovery (EUR) of shale gas wells. Petroleum Science, 18(5), $1450-1464$. doi:10.1016/j.petsci.2021.08.007.

[2] Mehana, M., Callard, J., Kang, Q., \& Viswanathan, H. (2020). Monte Carlo simulation and production analysis for ultimate recovery estimation of shale wells. Journal of Natural Gas Science and Engineering, 83, 103584. doi:10.1016/j.jngse.2020.103584.

[3] Wang, K., Li, H., Wang, J., Jiang, B., Bu, C., Zhang, Q., \& Luo, W. (2017). Predicting production and estimated ultimate recoveries for shale gas wells: A new methodology approach. Applied Energy, 206, $1416-1431$. doi:10.1016/j.apenergy.2017.09.119. 
[4] Karacaer, C. ., \& Onur, M. . (2012). Analytical Probabilistic Reserve Estimation by Volumetric Method and Aggregation of Resources. All Days. doi:10.2118/162875-ms.

[5] Sun, H., Cao, W., Li, J., Jia, W., Li, Y., Wu, Y., ... Meng, G. (2021). A material balance based practical analysis method to improve the dynamic reserve evaluation reliability of ultra-deep gas reservoirs with ultra-high pressure. Natural Gas Industry B, 8(1), 79-87. doi:10.1016/j.ngib.2020.07.004.

[6] Hu, Y., Weijermars, R., Zuo, L., \& Yu, W. (2018). Benchmarking EUR estimates for hydraulically fractured wells with and without fracture hits using various DCA methods. Journal of Petroleum Science and Engineering, 162, 617-632. doi:10.1016/j.petrol.2017.10.079.

[7] Okoro, E. E., Okoh, A., Ekeinde, E. B., \& Dosunmu, A. (2019). Reserve Estimation Using Decline Curve Analysis for Boundary-Dominated Flow Dry Gas Wells. Arabian Journal for Science and Engineering, 44(6), 6195-6204. doi:10.1007/s13369-019-03749-2.

[8] Al-Fatlawi, O. F. (2018). Numerical simulation for the reserve estimation and production optimization from tight gas reservoirs Doctoral dissertation, Curtin University, Public University in Perth, Australia.

[9] Rabiei, Minou, Ritu Gupta, Yaw Peng Cheong, and Gerardo A. Sanchez Soto. "A Novel Approach in Extracting Predictive Information from Water-Oil Ratio for Enhanced Water Production Mechanism Diagnosis.” The APPEA Journal 50, no. 1 (2010): 567. doi:10.1071/aj09034.

[10] Espinel Diaz, A. L., \& Barrufet, M. A. (2009). A Generalized Semi-analytical and Statistical Model to Estimate Oil and Water Production, Pore Volume Injected, and Ultimate Recovery in Mature Waterflooding Projects. All Days. doi:10.2118/122749ms.

[11] Ben Mahmud, H., Huque, M. M., \& Mandal, P. C. (2017). Developing Optimum Production Strategy of Kailashtilla Gas Field and Economic Analysis. ICIPEG 2016, 809-817. doi:10.1007/978-981-10-3650-7_70.

[12] Busahmin, B., Saeid, N. H., Alusta, G., \& Zahran, E. S. M. (2017). Review on hole cleaning for horizontal wells. ARPN Journal of Engineering and Applied Sciences, 12(16), 4697-4708.

[13] Ahlbrandt, T. S. (2001). The sirte basin province of Libya: sirte-zelten total petroleum system. US Department of the Interior, US Geological Survey, 1-29.

[14] Arps, J. J. (1945). Analysis of Decline Curves. Transactions of the AIME, 160(01), 228-247. doi:10.2118/945228-g.

[15] Bondar, V. V., \& Blasingame, T. A. (2002). Analysis and interpretation of water-oil-ratio performance. Journal Society of Petroleum Engineers.

[16] Blasingame, T. A., Ilk, D., \& Reese, P. D. (2007). Estimation of Reserves Using the Reciprocal Rate Method. All Days. doi:10.2118/107981-ms.

[17] Lo, K. K., Warner, H. R., \& Johnson, J. B. (1990). A Study of the Post-Breakthrough Characteristics of Waterflood. All Days. doi:10.2118/20064-ms.

[18] Chan, K.S. (1995) Water Control Diagnostic Plots. Paper SPE 30775 presented at the 1995 Annual Technical Conference and Exhibition, Dallas, TX, 22-25 October.

[19] Ershaghi, I., \& Omorigie, O. (1978). A Method for Extrapolation of Cut vs Recovery Curves. Journal of Petroleum Technology, 30(02), 203-204. doi:10.2118/6977-pa.

[20] Ershaghi, I., \& Abdassah, D. (1984). A Prediction Technique for Immiscible Processes Using Field Performance Data. Journal of Petroleum Technology, 36(04), 664-670. doi:10.2118/10068-pa.

[21] Lijek, S. J. (1989). Simple Performance Plots Used in Rate-Time Determination and Waterflood Analysis. SPE Annual Technical Conference and Exhibition. doi:10.2118/19847-ms.

[22] Yang, Z. (2009). A New Diagnostic Analysis Method for Waterflood Performance. SPE Reservoir Evaluation \& Engineering, 12(02), 341-351. doi:10.2118/113856-pa.

[23] Yang, Z. (2012). Production-Performance Diagnostics Using Field-Production Data and Analytical Models: Method and Case Study for the Hydraulically Fractured South Belridge Diatomite. SPE Reservoir Evaluation \& Engineering, 15(06), $712-724$. doi:10.2118/153138-pa.

[24] Yang, Z. (2017). Clarifying and Improving the Application of Waterflood Analytical Methods in X-Plot Conditions - From Empirical Approach to Analytical Approach. Day 3 Tue, April 25, 2017. doi:10.2118/185726-ms.

[25] Meulenbroek, B., Gargar, N. K., \& Bruining, H. (2020). An engineering approach to study the effect of saturation-dependent capillary diffusion on radial Buckley-Leverett flow. Computational Geosciences, 25(2), 637-653. doi:10.1007/s10596-02009993-y. 